NBER WORKING PAPER SERIES

\title{
WORK ENVIRONMENT AND "OPT-OUT" RATES AT MOTHERHOOD ACROSS HIGH-EDUCATION CAREER PATHS
}

\author{
Jane Leber Herr \\ Catherine Wolfram \\ Working Paper 14717 \\ http://www.nber.org/papers/w14717 \\ NATIONAL BUREAU OF ECONOMIC RESEARCH \\ 1050 Massachusetts Avenue \\ Cambridge, MA 02138 \\ February 2009
}

We would like to thank Marianne Bertrand, Dan Black, David Card, Constança Esteves-Sorenson, Claudia Goldin, Jason Grissom, Robert LaLonde, Ioana Marinescu, Annalisa Mastri, Emily Oster, Rebecca Ryan, Lucie Schmidt, Jesse Shapiro, and seminar participants at the University of Chicago, U.C. Berkeley, the University of Illinois at Urbana-Champaign, and the University of Michigan for their comments and suggestions. We would also like to thank Joshua Langenthal, Marci Glazer, Charles Jones, and Zachary Leber for the use of their Harvard anniversary reports, Jessica Chen, Margaret Gough, Cathy Hwang, Omar Jabri, Tatyana Shmygol and Jenny Zhuo for providing excellent research assistance, and Peter Jacobs for providing our estimated salaries. The views expressed herein are those of the author(s) and do not necessarily reflect the views of the National Bureau of Economic Research.

NBER working papers are circulated for discussion and comment purposes. They have not been peerreviewed or been subject to the review by the NBER Board of Directors that accompanies official NBER publications.

(C) 2009 by Jane Leber Herr and Catherine Wolfram. All rights reserved. Short sections of text, not to exceed two paragraphs, may be quoted without explicit permission provided that full credit, including (C) notice, is given to the source. 
Work Environment and "Opt-Out" Rates at Motherhood Across High-Education Career Paths Jane Leber Herr and Catherine Wolfram

NBER Working Paper No. 14717

February 2009

JEL No. J01,J13

\begin{abstract}
$\underline{\text { ABSTRACT }}$
Using data from the 2003 National Survey of College Graduates and a sample of Harvard alumnae, we study the relationship between work environment and the labor force participation of mothers. We first document a large variation in labor force participation rates across high-education fields. Mindful of the possibility of systematic patterns in the types of women who complete different graduate degrees, we use the rich information available in each dataset, and the longitudinal nature of the Harvard data, to assess the extent to which these labor supply patterns may reflect variation in the difficulty of combining work with family. While it is difficult to entirely rule out systematic sorting, our evidence suggests that non-family-friendly work environments "push" women out of the labor force at motherhood.
\end{abstract}

Jane Leber Herr

Harris School of Public Policy Studies

University of Chicago

1155 East 60th Street

Chicago, IL 60637

jlherr@uchicago.edu

Catherine Wolfram

Haas School of Business

University of California, Berkeley

Berkeley, CA 94720-1900

and NBER

wolfram@haas.berkeley.edu 


\section{Introduction}

One of the most profound social changes of the 20th century has been the dramatic increase in the number of women in the labor force. Recent statistics, however, suggest that the increase in female labor force participation began to level off in the late 1990s and early 2000s (Mosisa and Hippie, 2006). This has led to speculation about whether the "natural" rate of female labor force participation has been achieved (Goldin, 2006), whether this is instead a temporary slow-down driven by economic conditions (Boushey, 2005; Joint Economic Committee, 2008), or whether there are remaining policy, cultural, or social changes that would accommodate more women in the workforce (Drago and Hyatt, 2003).

Within the broader trends, much of the media discussion has focused on highly educated women leaving the labor force at motherhood. Most visibly this includes two cover articles, the "Opt-Out Revolution" in the New York Times magazine (Belkin, 2003) and "The Case for Staying Home" in Time Magazine (Wallis, 2004). In this paper we begin by documenting, however, that labor force participation rates of highly educated mothers vary markedly across professions. For example, among women with young children, the 2003 National Survey of College Graduates (NSCG) shows that 94 percent of MDs work, compared to only 75 percent of MBAs. Likewise, among Harvard graduates of the same cohort, 94 percent of MD mothers work, compared to only 72 percent of MBAs.

We next ask whether these patterns suggest that there are elements of the work environment - perhaps mutable with different policies or social norms - that drive mothers out of the labor force. If so, does variation in "family friendliness" across high-education professions help explain the large differences in labor force participation among mothers? Our aim is to assess whether work environment influences women's work decisions after motherhood, while mindful of the inherent differences in the set of women who pursue a given career path.

There is a vast literature on the factors that influence married women's labor supply (for recent examples see Goldin, 2006, and Blau and Kahn, 2007). Similar to this study, a subset 
of this literature has begun to focus on variables that elaborate on the traditional economic model by analyzing such factors as gender role attitudes (Fortin, 2005), social learning (Fogli and Veldkamp, 2008), and inter-generational preference transmission (Fernandez and Fogli, 2009). Our description of the potential influence of work environment, which assumes a minimum hours requirement that may vary across fields, lies outside the traditional model by placing this constraint on the labor supply decision.

One benefit of considering this question among highly educated women is that graduate degree is observable, and provides a clear delineation across which we expect systematic variation in work environment. Furthermore, highly educated women may be more sensitive to a given level of family friendliness. Although work environment may affect all women's utility, because these women are more likely to be married to high-earning men, they may have a greater capacity to respond by exiting the labor force. ${ }^{1}$ By using this set of women, we are therefore focusing on the "canaries in the coal mine", and can thus detect the effects of work environment when using a relatively blunt measure such as labor force participation.

At the same time, we might expect educated women to work in positions with greater benefits and professional standing, suggesting that they should have a greater capacity to adjust their work environment in response to motherhood (Tomlinson, 2004). If we then find evidence that work environment is correlated with labor force participation among these women, this may reflect an underestimate of the effect felt by women in lower ranks of the professional hierarchy.

We begin our analysis by discussing the elements likely to factor into a woman's labor supply decision at motherhood, focusing on two key components of taste: taste for time at home with one's children, and the identity value provided through one's career. In this section we provide a careful discussion of how the unobservable elements of taste will also affect sorting across graduate degrees, and across jobs within a field (as well as into motherhood

\footnotetext{
${ }^{1}$ Conversely, because these women are more likely to be the primary earner in their household, they may have greater parity with their spouse in home production, and may therefore be less likely to quit.
} 
itself). This insight helps guide our subsequent analysis. After introducing the data, we then discuss our identification strategy to address these two sources of bias in trying to tease out treatment from selection.

Among both the NSCG and Harvard graduate mothers, we focus our analysis on women with small children, to consider the effect of parenthood at the stage when demands at home are most intense. Given the long-run effects of labor supply gaps on women's career outcomes (Mincer and Ofek, 1982; Wood, Corcoran, and Courant, 1993; Bertrand, Goldin, and Katz, 2010), focusing on families with children not yet in the school system captures this key period in mothers' career and family life cycles. ${ }^{2}$

Our two data sources provide complementary benefits. The NSCG provides a more representative sample of highly educated mothers, but the information on spouses is limited and we observe only a cross-section. The Harvard sample is less representative but also more homogeneous, and the data include much richer information about spouses and marriages. Furthermore, in the Harvard data we can observe a subset of women both before and after their first birth. In both datasets, however, we have very rich information on education and careers. Furthermore, we find that the labor force participation rates across graduate degrees are almost identical in each.

As a first step, we capitalize on our rich data to assess whether the labor supply differences across career paths can be explained by systematic variation in women's characteristics, many of which will in part capture unobservable tastes for work or time at home. Even controlling for these rich sets of variables, in both the NSCG and Harvard data we find that the disparities in labor force participation by advanced degree remain remarkably unchanged.

This persistent difference in the propensity to remain working across women who complete different graduate degrees may therefore speak to systematic differences in the characteristics, or "family friendliness," of the jobs to which these degrees lead. Ideally, we would

\footnotetext{
${ }^{2}$ Because we focus on women with small children, we are not addressing "opt-in" patterns, or re-entry into the labor force.
} 
like to capture several dimensions of women's jobs, including both variation in "work-family" policies and in the culture of the workplace. ${ }^{3}$ Elements of the former will include the generosity of available maternity leave, formal part- or flex-time policies, or telecommuting. The latter will include de facto norms on the implications of using such policies, as well as the importance of factors such as "face time." Systematic variation in either of these characteristics may affect the family friendliness of jobs, that is, the relative utility they provide to women who must balance work and family commitments.

Because we cannot directly observe these characteristics, our measure of family friendliness is primarily built on the simplest dimension of workplace flexibility, the capacity to cut one's hours. As a first, coarse measure, we define as non-family friendly those settings where fewer than 20 percent of working mothers work part-time. For the Harvard sample, however, because we can observe employer, we can build a more refined measure that incorporates information from listings of family-friendly firms, such as that published by Working Mother magazine. For large for-profit firms, this will capture the richer dimensions that generate a family-friendly work environment, which are used to develop these rankings. By either measure and within both datasets, MBAs are most likely to work in a non-family-friendly environment before having children.

For the set of Harvard mothers who we can observe both before and after first birth, we then consider how pre-birth work environment affects post-birth labor supply. We find that work environment is a strong predictor of subsequent labor supply, but this may reflect the taste of women who choose family-friendly jobs before having children. We then use a controlfunction approach to predict sorting across pre-birth jobs based on the rich information observed at college. We find not only that these variables can predict whether a woman works in a family-friendly job, but also that factors observed after college but before children have little additional power in predicting this sorting. When we use this control function to assess the influence of pre-birth work environment, the results are unchanged. By these estimates,

\footnotetext{
${ }^{3}$ One might also consider the production function of a job as a central factor of its family friendliness, such as flexibility in the work itself or in who completes it. Evidence suggests, however, that the production function need not be a fixed characteristic of a given job (Claudia Goldin, as cited in Leonhardt, 2009).
} 
women working in family-friendly environments before their first birth are approximately 6 to 7 percentage points more likely to remain working after motherhood.

Lastly, we return to focus on the pattern in labor force participation by graduate degree, given the variation observed among women who by our definition are classified as working in non-family-friendly jobs before motherhood. Using data from both samples, as well as the findings of previous research, we find evidence suggesting that the non-family-friendly jobs held by MBAs are especially "unfriendly" for working mothers, in terms of both access to part-time positions, and the negative consequences of using available work-family policies.

Several caveats are in order in interpreting our results. First, because the second half of our analysis relies exclusively on the Harvard sample, it reflects the labor supply patterns of a particular set of mothers. As we document in the first half of the analysis, however, the labor supply patterns by degree are strikingly consistent across datasets. Thus, at least on this dimension, the Harvard women look surprisingly similar to this otherwise more representative sample of highly educated women.

More importantly, it is extremely difficult to rule out explanations based on selection. Nonetheless, considering both our inability to explain the observed differences in labor supply across advanced degrees, and our results on the importance of the family friendliness of a woman's job in explaining work propensity after motherhood, we find this evidence suggestive that a mother's work environment influences her decision about whether to remain in the labor force. Our results thus suggest that improved work-family policies or changes to social norms could drive labor force participation of women closer to parity with men.

This paper proceeds as follows. Section 2 begins with a discussion of the existing research on the influence of work environment. In Section 3 we introduce our framework for assessing a mother's labor force participation decision, and the related selection decisions across career paths and job types. Section 4 describes our two datasets, and how we define our measure of family friendliness. Given the underlying selection issues and the data at 
our disposal, Section 5 then lays out our empirical strategy, and Section 6 follows with our results. In Section 7 we discuss some possible interpretations of our findings, and in Section 8 we conclude.

\section{Existing Research on "Family Friendliness"}

As yet there has been relatively little economic research specifically on the effect of work environment, although some work focuses on its relationship with wages. For instance Johnson and Provan (1995) assess whether wage differences between those with and without work-family policies reflect a compensating differential or productivity gains, and Drago et al. (2001) study the willingness to pay for these policies among teachers. Nielsen, Simonsen, and Verner (2004) consider whether worker selection across firms with varying levels of such policies can help explain the "motherhood wage gap," and Anderson, Binder, and Krause (2003) offer variation in work flexibility as a potential explanation for differences in the motherhood wage gap by education. To our knowledge, no paper before this one has studied the effect of work environment on women's labor supply.

By comparison, within the sociology literature there is a significant body of research on the effect of work-family policies on the conflict between family and work commitments. ${ }^{4}$ This literature began with The Time Bind, the seminal work by Arlie Hochschild. Most comparable to our setting, Swiss and Walker (1993) look at this question among alumnae from Harvard's business, medical, and law schools.

Much of this literature focuses on job characteristics central to "family friendliness." This research considers not only variation in formal work-family policies, such as the availability of flex- and part-time schedules, but also the ways in which work environment and norms interact with these policies.

\footnotetext{
${ }^{4}$ Another strain of literature in the area of organizational behavior and human resource management focuses on the "business case" for these policies, such as their effect on labor turnover (Batt and Valcour, 2003), profits (Arthur and Cook, 2003), productivity (Clifton and Shepard, 2004), and shareholder value (Arthur and Cook, 2004).
} 
For instance, a number of studies discuss the relationship between the use of nonstandard schedules and the nature of the work itself (Berg, Kalleberg and Appelbaum, 2003). Swiss and Walker (1993) and Blair-Loy and Wharton (2004) focus on its predictability, and Boulis (2004) focuses on a woman's control over her own schedule. These papers discuss women selecting specialties to attain a controllable work schedule, such as primary care among doctors and avoiding litigation-heavy fields among lawyers.

Much of this research also focuses on variation in perceived barriers to using workfamily policies because of negative long-term career consequences (e.g., Eaton, 2003; BlairLoy and Wharton, 2002). For instance, in high-education careers where productivity is hard

to measure, long hours can become its signal (Landers, Rebitzer, and Taylor, 1996). In jobs with such work-hour norms, the use of part-time schedules can be especially harmful to career advancement (Wax, 2004).

In the theoretical framework that follows, we abstract away from the detail of workplace policies and norms, and consider only the simplest metric, hours worked. In Section 7, however, we will return to this discussion to provide insight for interpreting our results.

\section{Framework for Assessing Women's Career and Work Choices}

In this section we lay out a framework for assessing the influence of work environment on the labor force participation decision of highly educated mothers. Given that we focus on variation in work levels across women with different graduate degrees, we face the complication created by two selection processes:

1. the sorting of women across fields (as defined by graduate degree), and

2. within field, the sorting between family-friendly and non-family-friendly jobs.

This section describes how women make these decisions based on individual tastes, and the implications of this sorting. In the first half of the section we make the simplifying assumption that all jobs within a profession are homogeneous, leaving only the selection 
process across graduate degrees. We will then consider the implications of women sorting across job types within fields.

As a starting point, however, there is a third potential selection issue if work environment influences the initial decision to have children. If some women in non-family-friendly jobs respond by foregoing parenthood, the average taste for children among those who choose to have kids will be higher among mothers from a non-family-friendly environment. If this taste is positively correlated with taste for time at home, labor force participation rates among these women will be driven down accordingly. As we show in Appendix Section C, we find no evidence of variation in the propensity to have children among women from different work environments, so for the sake of simplicity, we ignore this issue here. ${ }^{5}$

Given this choice into parenthood, suppose a given mother $i$ decides whether to work in year $t$ based on the relative value of her marginal hour at work $\left(w_{i t}\right)$ and at home $\left(w_{i t}^{*}\right)$ (Heckman, 1974):

$$
\begin{aligned}
& w_{i t}=b_{0}+\sum_{j} b_{1 j} S_{i j}+b_{2} E_{i t}+b_{3} Z_{i t}+\nu_{i t}, \\
& w_{i t}^{*}=\beta_{0}+\beta_{1} h_{i t}+\beta_{2} K_{i t}+\beta_{3} Y_{i t}+\beta_{4} A_{i t}+\varepsilon_{i t} .
\end{aligned}
$$

In Equation (1), $S_{i j}$ is a vector of dummy variables indicating whether woman $i$ has a graduate degree of type $j\left(e . g .\right.$, MBA or MD), $E_{i t}$ is her work experience at time $t$, and $Z_{i t}$ are other factors that influence her offered wage. The elements of Equation (2) include hours worked $\left(h_{i t}\right)$, total children $\left(K_{i t}\right)$, her husband's salary $\left(Y_{i t}\right)$, and non-earned income $\left(A_{i t}\right)$.

\footnotetext{
${ }^{5}$ This lack of variation in the propensity to have children may indicate that women have difficulty assessing the impact of their work environment before they become mothers. In Appendix Section $\mathrm{C}$ we also test for selection into parenthood on ability. In both the NSCG sample and the Harvard longitudinal sample (but not the full Harvard sample), we find mild evidence of positive selection. By comparison, Bertrand et al., 2010 find no evidence of ability-based selection into parenthood among their MBA sample, but they do not address the possibility that mothers may select into different job types.
} 
The general practice is to assume that a woman works, $h_{i t}>0$, if the hourly wage is greater than her reservation wage assessed at $h=0, w_{i t}>w_{i t}^{*}(0) .{ }^{6}$ Such a woman will then choose her optimal labor supply, $h_{i t}^{*}$, where the two equations are equal. Yet this assumes that women have perfect control over their work hours.

Suppose, instead, that there exists a minimum hours requirement for a given career path, $h_{j}^{\text {min }}$, that varies across fields $j$ (but not across jobs within field $j$ ). Under this assumption, the relevant comparison is the offered wage versus the reservation wage at $h_{j}^{\min }:{ }^{7}$

$$
w_{i t}^{*}\left(h_{j}^{\text {min }}\right)=\beta_{0}+\beta_{1} h_{j}^{\text {min }}+\beta_{2} K_{i t}+\beta_{3} Y_{i t}+\beta_{4} A_{i t}+\beta_{5}\left(w_{i t} h_{j}^{\text {min }}\right)+\varepsilon_{i t} .
$$

Thus at a given point in time, a woman $i$ in field $j$ will work only if:

$$
\begin{array}{rl}
P\left(h_{i t}>0 \mid S_{i j}\right)= & P\left(w_{i t}\left(S_{i j}\right) \geq w_{i t}^{*}\left(h_{j}^{\text {min }}\right)\right) \\
=P & P\left(b_{0}+b_{1 j} S_{i j}+b_{2} E_{i t}+b_{3} Z_{i t}+\nu_{i t} \geq\right. \\
& \left.\quad \beta_{0}+\beta_{1} h_{j}^{\text {min }}+\beta_{2} K_{i t}+\beta_{3} Y_{i t}+\beta_{4} A_{i t}+\beta_{5}\left(w_{i t} h_{j}^{\text {min }}\right)+\varepsilon_{i t}\right) .
\end{array}
$$

Now consider the observation that among mothers, MDs are much more likely to work than MBAs: $P\left(h_{i}>0 \mid S_{M D}\right)>P\left(h_{i}>0 \mid S_{M B A}\right)$. If $b_{1 M D}=b_{1 M B A}$, and all of the variables in Equation (4) are equally distributed, this would imply that $h_{M D}^{\min }<h_{M B A}^{\min }$ - that being a doctor is more easily combined with family than working in the business world.

Yet the elements of Equation (4) are unlikely to be equal among women in different fields. For instance, since many meet their spouse in graduate school, we would expect systematic variation in their husbands' salaries. We might also expect the number of children to vary if women time births around schooling of different lengths.

\footnotetext{
${ }^{6}$ This assumes that women make their current-period decision without factoring in future consequences. A more complete specification would consider the path of period-specific labor supply in a life-cycle setting. Current choices may affect future wage offers not only through experience, $E_{i t}$, but also if there exist penalties for labor supply gaps, which may vary across fields $j$ (Bertrand et al., 2010).

${ }^{7}$ The minimum hours requirement creates a new corner solution, where the choice at the margin is the decision to work $h_{j}^{\text {min }}$ hours and earn $w_{i t} h_{j}^{\text {min }}$, explaining the additional term in Equation (3).
} 
More importantly, we know that women are not randomly assigned across fields. Each woman $i$ will choose the graduate degree $S_{j}$ that maximizes her expected lifetime utility, where $E\left[U_{i j}\right]$ reflects the difference between her expected benefits and costs of career path $j$ :

$$
\begin{aligned}
& E\left[\operatorname{Cost}_{i j} \mid S_{i j}\right]=E\left[\text { tuition }_{j} \mid S_{i j}\right]+E\left[(\text { years in school })_{j} \mid S_{i j}\right] *(\text { forgone wages } / \text { year })_{i}, \\
& E\left[\text { Benefit }_{i j} \mid S_{i j}\right]=\left(E\left[\Delta \text { earnings }_{i} \mid S_{i j}\right]+\psi_{i j}\right) * E\left[(\text { years working })_{i} \mid S_{i j}\right] .
\end{aligned}
$$

The costs include the tuition and years of schooling, while the benefits include the expected change in earnings, plus a factor $\psi_{i j}$ that reflects the value of a woman's professional identity from working in field $j$, each multiplied by the expected number of years worked. ${ }^{8}$

Notice two things. First, $h_{j}^{\text {min }}$ will enter into the expected benefits of a given career path through its influence on years worked: $\left.E[\text { (years working })_{i} \mid S_{i j}\right]=E\left[\sum_{t} P\left(h_{i t}^{*} \geq h_{j}^{\text {min }}\right)\right] .{ }^{9}$ Second, we can decompose the error term in the reservation wage into three elements, $\varepsilon_{i t}=$ $\zeta_{i t}-\psi_{i j}+\omega_{i t}$, where $\zeta_{i t}$ reflects her taste for time at home with her children, and $\omega_{i t}$ captures all other factors. ${ }^{10}$ Since $\psi_{i j}$ can only be enjoyed if working, it enters negatively into $\varepsilon_{i t}$.

Given Equation (4), we can see that $\zeta$ will likewise enter into the expected benefits of a given career path, again through an influence on the number of years a woman expects to work. Thus unobserved elements of taste, $\theta=(\zeta, \psi)$, as well as $h_{j}^{m i n}$, will influence not only a woman's labor supply decision at a specific point in time, but also the initial selection process across fields.

Now consider the implications of relaxing the assumption that all jobs within each career path are homogeneous. In truth the types of jobs within any field will vary in their work environment, and women may include this information on the mix of family friendliness

\footnotetext{
${ }^{8}$ Much of the popular press and sociology literature discuss the personal identity issues associated with leaving one's job (Wallis, 2004; Swiss and Walker, 1993; Stone and Lovejoy, 2004).

${ }^{9}$ This equation is a slight over-simplification. For the years in which $h^{*}<h^{\text {min }}$, the threshold of whether a women works reflects the difference in utility of working 0 versus $h^{\text {min }}$ hours.

${ }^{10}$ This formulation assumes all women anticipate having children. As written, $\zeta_{i t}$ may vary over time, for instance with the age of a woman's children.
} 
in their initial schooling decision. Likewise, after completing their education, we should also expect women to sort across these job environments based on taste (Polachek, 1977).

Challenge \#1: Effect of Variation in $\psi$

Given the large variation in cost across graduate degrees, all else equal, the mean value of $\psi$ must be higher for women who choose a high-cost field over a low-cost field (e.g., an MD instead of an MBA). This systematic difference will be necessary to increase their expected number of years worked - thus offsetting the higher cost - and will in turn increase their labor force participation at any point in time. ${ }^{11}$ Thus when considering whether variation in labor supply across fields speaks to variation in work environment, if we cannot fully control for this element of taste, any remaining differences between high- and low-cost fields may speak only to variation in $\psi{ }^{12}$

Challenge \#2: Effect of Variation in $\zeta$

Consider the distribution of $\zeta$ among the whole population of women. There exists some threshold, $\zeta^{H}$, above which all women will leave the labor force at motherhood - regardless of their work environment - because their $h^{*}$ will fall below the minimum hours requirement in all fields. Among these women the family friendliness of their pre-birth job is irrelevant, and they will choose non-family-friendly options if they offer systematically higher wages.

Exclusive of these women, among the remainder of the population we should expect those in the upper part of the $\zeta$ distribution to choose family-friendly fields, or family-friendly jobs within a given field. Thus if non-family-friendly jobs pay more, the sorting across job types will switch directions at two points in the $\zeta$ distribution: women with both low and very high levels of $\zeta$ may systematically choose to work in non-family-friendly environments before they have children.

\footnotetext{
${ }^{11}$ By this same argument, if the distribution of $\psi$ is instead equal across fields, women in high-cost fields must heave systematically lower $\zeta$.

${ }^{12}$ Likewise, if for some reason those women who select family-friendly jobs have systematically higher $\psi$, any greater labor force participation among these mothers could arise through this variation in taste rather than through a treatment effect of work environment.
} 
The implication of this sorting depends on which part of the $\zeta$ distribution is captured in our population of highly educated women. If our samples primarily exclude women in the right-hand tail of the $\zeta$ distribution - such that we only capture the lower switching point - the mean value of $\zeta$ among women who choose family friendly jobs before children will be higher than the mean among women working in non-family-friendly jobs: $E[\zeta \mid F F]>$ $E[\zeta \mid n F F]$. If instead our samples include women with $\zeta \geq \zeta^{H}$, the opposite may hold. ${ }^{13}$

We suspect that the former is more likely. Why would women with very high $\zeta$ invest in a graduate degree? ${ }^{14}$ Given this likely direction of sorting, because the mean value of $\zeta$ will be higher among women who choose family-friendly jobs, their post-children distribution of $h^{*}$ will lie to the left of the distribution among women we observe in non-family-friendly environments. Thus for a given value of $h^{\text {min }}$, all else equal, women who choose familyfriendly jobs should be more likely to leave the labor force at motherhood.

Consider this in terms of measuring the causal effect of work environment on labor force participation. If a family-friendly environment has a positive effect on mothers' work levels, unless we can fully absorb variation in $\zeta$, our measure will understate the true causal effect. If, however, sorting on $\zeta$ occurs in the opposite direction, the reverse will hold and our coefficient will be too large.

Throughout this section, however, we are likely overstating the level of bias created by variation in taste by assuming complete information. In truth, women make choices under great uncertainty. It is difficult to gauge the family friendliness of any job before the fact, and appreciably harder to determine the overall level of an entire field, especially since it

\footnotetext{
${ }^{13}$ If, however, the same fields that have low $h_{\min }$ likewise have lower penalties for time off, those high- $\zeta$ women who anticipate a return to work may instead choose a family-friendly field $j$ before having children.

${ }^{14}$ An intriguing possibility is that high- $\zeta$ women use graduate school as a marriage market for high-earning spouses. Considering the three high-salary professions - doctors, lawyers, and businessmen - the least costly choice would be to enroll in business school. (Men with MBAs might likewise have a greater taste for high- $\zeta$ wives.) Using the Harvard data, comparing the labor force participation rates of women who are paired before graduate school versus those who marry a classmate, a comparison across degrees finds no evidence suggesting this phenomenon.
} 
will change over time, and at potentially varying rates across the set of alternatives $j .{ }^{15}$

Furthermore, women may not be fully cognizant of their value of $\zeta$ before they have their first child, which for most occurs after they have started their first post-graduate job. In the Harvard sample, for example, the average age at first birth is 32 , on average 7 to 9 years after applying to graduate school. Thus at each stage, the effects of selection are likely to be dampened by this lack of complete information.

\section{Data and Descriptive Statistics}

In this section we begin by introducing the NSCG and Harvard data (see the data appendix for greater detail), and compare the educational and family formation patterns of these two populations of women. We then introduce our measures of family friendliness.

\subsection{NSCG Data}

The 2003 wave of the National Survey of College Graduates captures a sample of US residents who hold at least a bachelors degree (completed by April 1st, 2000), and who lived in the US in both 2000 and 2003. For each respondent we observe highest degree attained, grouped by $\mathrm{PhD}$, MA, or a professional degree. We distinguish MBAs from MAs based on graduate field of study (business); among those with professional degrees, we distinguish JDs, MDs, and those with specialized MAs, based on field of study and occupation.

The NSCG captures enormously rich information on education and employment (e.g., occupation, sector, salary, and hours worked). Unfortunately the survey provides more limited demographic information, especially with respect to each woman's spouse. In particular, we do not observe spouse's earnings.

We focus our analysis on women who have children under the age of 6 , and, for the sake of homogeneity, we include only those who have completed a graduate degree. ${ }^{16}$ We

\footnotetext{
${ }^{15}$ When choosing across graduate programs women will also have, at best, a rough estimate of their spouse's future earnings, especially since most are not yet married.

${ }^{16}$ For the same reason, we also exclude women who completed their BA outside the US or after they turned
} 
also limit our sample to married women, who will have another potential source of income beyond their own earnings. This provides a sample of 1,404 women, with a mean age of 36.2.

\subsection{Harvard Graduate Data}

We collect data from the 10th and 15th anniversary reports for the graduating classes of 1988 through 1991, focusing on women observed 15 years after earning their BA (in 2003 to 2006), when they are approximately $37 .{ }^{17}$ Among these classes, 55 percent of women responded to the 15th-year survey; see Appendix B.1 for a discussion of the response patterns.

The anniversary reports provide rich professional and demographic information. The professional data include detailed information on post-graduate education (including the program attended, institution, and year of graduation), and current occupation and firm. The personal information include spouse's detailed education and occupation, and children's year of birth.

We supplement this with data collected from the yearbook, including college activities (major and varsity sports participation), family background (region of origin, private school attendance, and race/ethnicity), and dormitory. Students chose dorms at the end of their first year, and many were known to have a certain identity (e.g., "artsy", "jocks", "legacy", or "pre-med"). As discussed below, we find that this information predicts much about these women's subsequent career decisions.

In the anniversary reports many graduates also write a narrative describing their life and achievements over the previous five years. Among those respondents moving into parenthood, this often focuses on a description of life after children, including a discussion of their work choices. From these comments, as well as those reporting their occupation as "mom" 25 , and those who attended community college.

${ }^{17}$ Goldin and Katz (2008) report preliminary results from a large data collection effort on several cohorts of Harvard and Radcliffe graduates (the "Harvard and Beyond" study sample). Their study depicts broad trends in various schooling, family, and work choices made by men and women graduating around 1970, 1980, and 1990. In recent work Goldin and Katz use this data to explore the question of variation in labor force participation rates among highly educated women (John R. Commons Award Lecture, ASSA, January, $3,2010)$. Our analysis relies on a different data source, although our sample overlaps with their 1990 cohort. See Section 4 and Appendix B for a more detailed discussion of our data. 
or its equivalent, we can measure the current employment status of Harvard mothers. ${ }^{18}$

One limitation of the Harvard data is that we lack information on earnings. We therefore hired a career consultant to impute salaries for both the graduates and their spouses. We provided him our rich information on an individual's education, location, occupation, and firm. Because he did not observe gender or parental status, these estimates reflect gender-neutral salary levels associated with a given career. We estimate "gendered" wages from these salary values using detailed sector/industry/occupation average hours and gender wage gaps, as described in detail in Appendix B.2. ${ }^{19}$

As with the NSCG, we limit ourselves to women who are married, but include women with children of all ages and those with no graduate degree. ${ }^{20}$ This gives us a sample of 934 women. We also focus on the subset of Harvard mothers who we observe both before and after first birth, the "longitudinal" sample. This includes the 286 women observed both 10 and 15 years after graduation, who had their first child within this period, who provide sufficient work information at both points, and who do not hold either an MD or PhD. ${ }^{21}$

\subsection{Comparing NSCG and Harvard Mothers}

Table 1 compares education and family formation patterns for all female college graduates in their late 30s in the NSCG and Harvard datasets. The first lines show that Harvard graduates attain much more education than the more representative sample of US college

\footnotetext{
${ }^{18}$ Using data from married Harvard couples, we test for two potential sources of bias: that stay-at-home mothers under-respond to the survey or fail to report their at-home status, or that at-home mothers are over-represented. We find no evidence that at-home mothers are under-represented, and weak evidence that they may be slightly over-represented.

${ }^{19}$ Appendix B.2 also discusses whether our initial salary estimates are systematically understated. We conclude that spouse's, but not own, earnings may be too low. Because this pattern may vary by spouse's graduate degree, we include this additional factor directly in our analysis.

${ }^{20}$ Nine percent of the Harvard mothers have a youngest child age 6 or older (of which half are exactly 6 ). We do not exclude women without graduate degrees because this sample is much more homogenous.

${ }^{21}$ As discussed in Section 5, we exclude the MDs and $\mathrm{PhDs}$ because these reflect much higher-cost graduate degrees, and are therefore likely to introduce the strongest selection on taste. On a more practical matter, we also exclude them because too many are still in training 10 years after graduation, thus we lack sufficient information on their pre-birth (post-training) work environment to assess its influence on their subsequent work patterns. For instance, 43 percent of women who hold a $\mathrm{PhD}$ by 15 years after graduation are still in graduate school or are completing post-doctoral fellowships 5 years earlier, and 58 percent of MDs are completing their residency or fellowships, or are still in medical school.
} 
Table 1: Comparison of Education and Family Formation Patterns

\begin{tabular}{|c|c|c|c|c|c|c|c|}
\hline & All & MD & PhD & JD & MBA & MA & None \\
\hline \multicolumn{8}{|c|}{ Distribution of Highest Graduate Degrees (\%): } \\
\hline NSCG & - & $1.6^{* *}$ & $1.6^{* *}$ & $2.7^{* *}$ & $4.2^{* *}$ & $22.1^{* *}$ & $67.8^{* *}$ \\
\hline Harvard & - & $14.7^{* *}$ & $14.4^{* *}$ & $20.4^{* *}$ & $13.8^{* *}$ & $18.7^{* *}$ & $18.0^{* *}$ \\
\hline \multicolumn{8}{|c|}{ Married (\%): } \\
\hline NSCG & 76.1 & 77.5 & 70.9 & $65.8^{*}$ & 75.3 & 74.1 & 78.0 \\
\hline Harvard & 77.1 & 81.2 & 73.5 & $76.5^{*}$ & 77.6 & 75.8 & 78.1 \\
\hline \multicolumn{8}{|c|}{ If Married, Children (\%): } \\
\hline NSCG & 80.7 & 78.5 & 74.9 & 81.3 & 80.8 & 78.3 & $82.3^{*}$ \\
\hline Harvard & 79.6 & 85.1 & 72.7 & 82.4 & 84.7 & 76.9 & $76.2^{*}$ \\
\hline \multicolumn{8}{|c|}{ If Married \& Children, Total Kids (\#): } \\
\hline NSCG & $2.18^{* *}$ & $2.21^{* *}$ & 1.90 & 2.08 & $2.10^{*}$ & $2.09^{* *}$ & $2.24^{* *}$ \\
\hline & $(0.97)$ & $(0.95)$ & $(0.86)$ & $(0.79)$ & $(0.88)$ & $(0.92)$ & $(1.00)$ \\
\hline Harvard & $1.88^{* *}$ & $1.84^{* *}$ & 1.74 & 1.94 & $1.88^{*}$ & $1.86^{* *}$ & $1.97^{* *}$ \\
\hline & $(0.79)$ & $(0.67)$ & $(0.78)$ & $(0.74)$ & $(0.85)$ & $(0.88)$ & $(0.79)$ \\
\hline \multicolumn{8}{|c|}{ If Married \& Children, Kids Under Age $6(\%)$ : } \\
\hline NSCG & $73.4^{* *}$ & $83.3^{* *}$ & 83.9 & 89.7 & $86.9^{+}$ & $74.6^{* *}$ & $69.9^{* *}$ \\
\hline Harvard & $90.8^{* *}$ & $96.1^{* *}$ & 89.7 & 92.9 & $92.8^{+}$ & $92.8^{* *}$ & $80.4^{* *}$ \\
\hline
\end{tabular}

NOTES:

Values reflect means (and for total children, standard deviations). The NSCG sample includes women ages 35 to 40 who completed their BA in the US by the year they turned 25 and never attended community college $(N=5237)$. The Harvard sample includes all women in the classes of 1988 to 1991 observed 15 years after college graduation $(N=1522)$. Given the NSCG's focus on science and technology, we apply survey weights to calculate the education proportions. Significance levels reflect the ability to reject the null of equality of each proportion within the Harvard and NSCG samples $\left(+\right.$ significant at $10 \%,{ }^{*}$ at $5 \%$, and ${ }^{* *}$ at $1 \%$ ). See Appendix Section $\mathrm{C}$ for a discussion of whether the proportion who have children varies across degrees within samples.

graduates. Despite these large differences, we see that the proportion who are married, and among those, the proportion who have children, is surprisingly similar across these two samples, both overall and by graduate degree. Given that Harvard women have fewer and younger children, however, it is clear that Harvard graduates delay parenthood for longer. ${ }^{22}$

Table 2 next compares the employment rates of our two samples of mothers to those for women and men who have not yet had children. ${ }^{23}$ (See Appendix Tables A-1 and A-

\footnotetext{
${ }^{22}$ As shown in Appendix Tables A-1 and A-3, however, given our restriction of the NSCG to women with graduate degrees and children under age 6 , the number of kids is very similar in the two samples used.

${ }^{23}$ See the notes to Table 2 for detail on the sample criteria for the population without children. Our goal is to measure employment rates among women who currently do not have children, but who may do so in the future, since the behavior of women who choose to stay childless may not reflect the pre-birth work patterns of women who later become mothers.
} 
Table 2: Employment Rates by Parental Status

\begin{tabular}{|c|c|c|c|c|c|c|c|}
\hline & All & MD & PhD & JD & MBA & MA & None \\
\hline \multicolumn{8}{|c|}{ NSCG Sample } \\
\hline \multicolumn{8}{|l|}{ No Children: } \\
\hline \multirow[t]{2}{*}{ Women (\%) } & 93.8 & 97.3 & 92.8 & 92.2 & 97.1 & 93.3 & - \\
\hline & [915] & [73] & {$[69]$} & {$[90]$} & {$[70]$} & [613] & - \\
\hline \multirow[t]{2}{*}{ Men (\%) } & 93.3 & 98.6 & 95.6 & 87.3 & 89.1 & 93.6 & - \\
\hline & [824] & {$[70]$} & [113] & {$[63]$} & {$[92]$} & [486] & - \\
\hline \multirow[t]{2}{*}{ Mothers (\%) } & 77.7 & 94.3 & 84.1 & 78.1 & 75.2 & 74.6 & - \\
\hline & [1404] & [106] & [189] & [114] & [141] & {$[854]$} & - \\
\hline \multicolumn{8}{|c|}{ Harvard Sample } \\
\hline \multicolumn{8}{|l|}{ No Children: } \\
\hline \multirow[t]{2}{*}{ Women (\%) } & 98.2 & 100.0 & 99.1 & 98.0 & 96.6 & 97.4 & 98.5 \\
\hline & [1063] & [162] & [112] & [253] & [146] & [193] & [197] \\
\hline \multirow[t]{2}{*}{ Men (\%) } & 97.8 & 100.0 & 98.5 & 98.1 & 95.9 & 97.7 & 97.7 \\
\hline & [1348] & [167] & [136] & [315] & [246] & [131] & [353] \\
\hline \multirow[t]{2}{*}{ Mothers (\%) } & 78.1 & 94.2 & 85.5 & 77.6 & 71.7 & 72.9 & 68.7 \\
\hline & [934] & [154] & [117] & [196] & [138] & [166] & [163] \\
\hline
\end{tabular}

NOTES:

Data reflect the mean employment rates, with sample sizes listed in brackets. In the NSCG, the "no children" sample include all respondents who meet the sample criteria listed Section 4.1, but who are childless and are between the ages of 26 and 33. In the Harvard sample the "no children" sample are those observed in the 10th-year reunion who have no children, and who have already completed their schooling. The data for the NSCG and Harvard mothers reflect the analysis samples discussed in Sections 4.1 and 4.2, respectively.

3 for more summary statistics for the NSCG and Harvard samples, respectively.) Notice that employment rates among women without children are very high, and vary little across graduate degrees. For instance, in both the NSCG and Harvard samples, 97 percent of the childless female MBAs are working (significantly more than MBA men in the NSCG).

Among mothers, however, the proportion working varies strongly by field. In the NSCG 94 percent of MDs work, compared to only 75 percent of MBAs and MAs. Among the Harvard sample, an equal 94 percent of MDs work, compared to 72 to 73 percent of MBAs and MAs, and 69 percent of women with no graduate degree. ${ }^{24}$ The similarity of these labor force participation rates are striking, especially given that the Harvard sample are a much more select group of women. ${ }^{25}$ Furthermore, these rates are high compared to

\footnotetext{
${ }^{24}$ Women in the Harvard longitudinal sample have higher labor force participation: 84 percent for the JDs, 74 percent for the MBAs, and 81 percent for both the MAs and those with no additional degree.

${ }^{25}$ Likewise, among their sample of Harvard business, law, and medical school alumnae who graduated 15
} 
those for women with only a BA, calling into question the media focus on the "excessive" opt-out rates among highly educated mothers. ${ }^{26}$

\subsection{Defining Family Friendliness}

As the first step in defining family friendliness, we use the distribution of hours worked among mothers in different types of jobs as an indication of the flexibility of the environment. The NSCG provides detailed data on hours worked, employer sector (e.g., for-profit, non-profit, government), employer size, and occupation. We use these data - by graduate degree - to distinguish across types of work environments, for instance large versus small firms, or in education, working as a teacher versus in another capacity.

We use the hours distribution of working mothers to define our family-friendliness measure because we think it will reflect the existence of a minimum hours requirement. In fields with no such threshold, we expect observed hours to approximate $h^{*}$, women's ideal work hours after children. In fields with a minimum requirement, however, we expect hours to be truncated, with women with low values of $h^{*}$ forced to leave the labor force.

Within each work environment, we define as non-family friendly those settings in which the 25th percentile of the hours distribution for working mothers is full-time, or fewer than 20 percent work part-time. As the top panel of Table 3 shows, these two criteria capture exactly the same fields: big firms, the government, and teaching. ${ }^{27}$ Even though we consider this separately by graduate degree, the patterns are the same across each.

A comparison of the hours distribution among women with and without children suggests that our criteria capture those fields in which work hours are more constrained. Com-

to 25 years before our samples, Swiss and Walker (1993) find similar results. By their 30s and 40s, only 75 percent of MBA mothers are working, compared to 89 percent of JDs and 96 percent of MDs.

${ }^{26}$ By comparison, among the NSCG married mothers of small children who hold only a BA (but who otherwise meet the criteria listed in Section 4.1), only 66.4 percent are working.

${ }^{27}$ Some may find this designation for teaching surprising. Because our measure may be slightly misspecified for these women (since it is based on weekly hours and ignores that they get the summers off), we distinguish teachers from those in other non-family-friendly environments in our specifications reported in Table 7. Another reason for this is that we suspect that women who select teaching - working with other people's children - may have a systematically higher desire to stay home with their own. 
Table 3: Labor Supply Patterns of NSCG Mothers and Non-Mothers

\begin{tabular}{|c|c|c|c|c|c|c|c|}
\hline & $\begin{array}{l}\text { Big } \\
\text { Firm }\end{array}$ & $\begin{array}{l}\text { Small } \\
\text { Firm }\end{array}$ & $\begin{array}{l}\text { Non- } \\
\text { profit }\end{array}$ & $\begin{array}{l}\text { School } \\
\text { Teacher }\end{array}$ & $\begin{array}{l}\text { Educ- } \\
\text { ation }\end{array}$ & $\begin{array}{l}\text { Govern- } \\
\text { ment }\end{array}$ & $\begin{array}{c}\text { Self- } \\
\text { Employed }\end{array}$ \\
\hline \multicolumn{8}{|c|}{ Women With Children: } \\
\hline \multicolumn{8}{|l|}{ MA } \\
\hline$\%<35 \mathrm{hrs} / \mathrm{wk}$ & 17.5 & 46.0 & 42.2 & 12.1 & 36.1 & 18.5 & 56.4 \\
\hline $25^{\text {th }}$ p-tile (hrs/wk) & 40 & 21 & 24 & 40 & 21 & 38 & 15 \\
\hline Sample size & 514 & 150 & 204 & 603 & 590 & 227 & 275 \\
\hline \multicolumn{8}{|l|}{ JD } \\
\hline$\%<35 \mathrm{hrs} / \mathrm{wk}$ & 19.1 & 43.8 & 29.6 & - & - & 10.5 & 46.2 \\
\hline $25^{\text {th }}$ p-tile (hrs/wk) & 38 & 20 & 30 & - & - & 37 & 15 \\
\hline Sample size & 47 & 32 & 27 & - & - & 38 & 65 \\
\hline \multicolumn{8}{|l|}{ MBA } \\
\hline$\%<35 \mathrm{hrs} / \mathrm{wk}$ & 14.6 & 40.7 & 31.1 & - & - & 15.4 & 51.1 \\
\hline $25^{\text {th }}$ p-tile (hrs/wk) & 40 & 21 & 32 & - & - & 40 & 17 \\
\hline Sample size & 192 & 27 & 61 & - & - & 26 & 45 \\
\hline \multicolumn{8}{|c|}{ Women Without Children: } \\
\hline \multicolumn{8}{|l|}{ MA } \\
\hline$\%<35 \mathrm{hrs} / \mathrm{wk}$ & 4.5 & 16.9 & 8.9 & 2.6 & 28.4 & 3.2 & 15.6 \\
\hline $25^{\text {th }}$ p-tile (hrs $/$ wk) & 40 & 37 & 40 & 40 & 30 & 40 & 36 \\
\hline Sample size & 399 & 118 & 203 & 312 & 507 & 219 & 147 \\
\hline \multicolumn{8}{|l|}{ JD } \\
\hline$\%<35 \mathrm{hrs} / \mathrm{wk}$ & 1.7 & 0.0 & 19.0 & - & - & 1.8 & 17.5 \\
\hline $25^{\text {th }}$ p-tile (hrs $/$ wk) & 46.5 & 40 & 38 & - & - & 40 & 40 \\
\hline Sample size & 60 & 21 & 21 & - & - & 55 & 40 \\
\hline \multicolumn{8}{|l|}{ MBA } \\
\hline$\%<35 \mathrm{hrs} / \mathrm{wk}$ & 0.6 & 0.0 & 11.3 & - & - & 0.0 & 13.0 \\
\hline $25^{\text {th }} \mathrm{p}$-tile (hrs/wk) & 40 & 45 & 40 & - & - & 40 & 35 \\
\hline Sample size & 158 & 21 & 53 & - & - & 25 & 23 \\
\hline
\end{tabular}

\section{NOTES:}

Environments defined as non-family-friendly are distinguished in bold. (As discussed in footnote 21, we do not include MDs and PhDs.) Relative to other degrees, a much higher proportion of MAs work in education, so we distinguish education from other non-profits, and within education, distinguish primary-and secondary-school teachers from those working in other capacities. To increase the sample sizes, we use NSCG mothers of children under age 12, and for the set of non-mothers we include women ages 25 to 40 . We also do not exclude those who attended a community college or university outside of the US, or who completed their BA after age 25, although among the mothers we still include only those who are married. In both instances, the patterns are the same if we instead use these exclusion restrictions.

paring the top and bottom panels of Table 3, whereas non-mothers in "family-friendly" fields are generally working full-time, mothers are working 10 to 25 fewer hours per week. By comparison, in the "non-family-friendly" fields, the 25th percentile among mothers is, with one exception, at most 3 hours per week lower than among non-mothers. We take this as evidence of a limit on women's capacity to cut their work hours in these environments. 
Lastly, because we observe firm names in our Harvard data, for the longitudinal sample we build a richer measure of work environment by using firm-specific family friendliness rankings. In particular, we reclassify as family friendly those large firms that are included in the list of "Top Ten Family-Friendly Firms" as compiled by the Yale Law Women, or the list of "Best Places" for working mothers by Working Mother magazine. ${ }^{28}$ Using this data, 20 percent of the Harvard women in large firms are re-categorized as working in a family-friendly environment, including 25 percent of MBAs and JDs.

One concern in using these definitions is that our initial measure of "family friendliness" is endogenous to sorting across work environments. As discussed in Section 3, women with high taste for time at home with their children, $\zeta$, may select more family-friendly fields. Among these women we would therefore expect $h^{*}$ to shift down by more at motherhood. Thus our observation that mothers in certain fields are more likely to be working part-time may reflect a higher proportion wanting to work part-time, not a higher proportion being allowed to work part-time.

A second concern is tautological. If the hours distribution in "non-family friendly" fields arises because women with low $h^{*}$ quit, we are effectively using a measure of the proportion of women who quit to predict the proportion of women who quit, albeit in another dataset.

An alternative approach would be to rely on the labor supply patterns of women without children to gauge access to part-time schedules. Looking at the bottom panel of Table 3, we see roughly two norms - those environments in which fewer than 5 percent work part-time, and those where 10 to 20 percent do so.

If we instead used this data to build our definition of work environment, setting the threshold at 5 percent, the set of jobs classified as non-family friendly would be almost

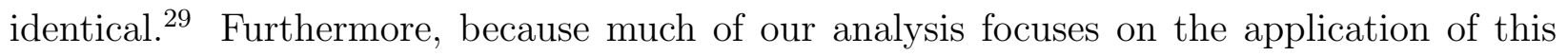

\footnotetext{
${ }^{28}$ See Appendix Table A-4 for a listing of the firms included in each of these sources.

${ }^{29}$ The two exceptions are JDs and MBAs working for small firms. We rely on our original criteria rather than this definition because of this discrepancy. If the data for non-mothers suggest JDs and MBAs in small firms cannot work part-time, how can it be that 40 percent of mothers do so? As a check, however, see
} 
definition to the Harvard sample, this part of the classification will not be endogenous to the labor supply choices of the Harvard women themselves. In addition, the main parts of our analysis use the more refined measure of work environment, which incorporates direct information about the family friendliness of large firms.

Table 4: Distribution of Family Friendliness Before Children

\begin{tabular}{lccccc}
\hline \hline & All & JD & MBA & MA & None \\
\hline NSCG: & & & & & \\
\hline Non-family-friendly (\%) & 50.6 & 57.4 & 61.4 & 48.4 & - \\
Big firm & $\mathbf{2 2 . 9}$ & $\mathbf{2 9 . 7}$ & $\mathbf{5 3 . 4}$ & $\mathbf{1 8 . 4}$ & - \\
Government & $\mathbf{1 3 . 5}$ & $\mathbf{2 7 . 7}$ & $\mathbf{8 . 0}$ & $\mathbf{1 2 . 2}$ & - \\
School teacher & $\mathbf{1 4 . 3}$ & - & - & $\mathbf{1 7 . 8}$ & - \\
Small firm & 7.3 & 10.9 & 8.0 & 6.8 & - \\
Non-profit & 11.0 & 11.9 & 21.6 & 11.7 & - \\
Other education & 22.9 & - & - & 26.8 & - \\
Self-employed & 8.1 & 19.8 & 9.1 & 6.4 & - \\
Sample Size: & $\mathbf{9 4 3}$ & $\mathbf{1 0 1}$ & $\mathbf{8 8}$ & $\mathbf{7 5 4}$ & - \\
& & & & & \\
Harvard Longitudinal Sample: & & & & & \\
\hline Non-family-friendly (NSCG-compatible, $\%)$ & 57.0 & 62.0 & 71.2 & 36.0 & 60.4 \\
Non-family-friendly (firm-specific, \%) & 47.9 & 51.1 & 53.0 & 36.0 & 52.8 \\
Big non-FF-firm & $\mathbf{3 5 . 0}$ & $\mathbf{3 2 . 6}$ & $\mathbf{5 1 . 5}$ & $\mathbf{1 6 . 0}$ & $\mathbf{4 5 . 3}$ \\
Government & $\mathbf{9 . 4}$ & $\mathbf{1 8 . 5}$ & $\mathbf{1 . 5}$ & $\mathbf{9 . 3}$ & $\mathbf{3 . 8}$ \\
School teacher & $\mathbf{3 . 5}$ & - & - & $\mathbf{1 0 . 7}$ & $\mathbf{3 . 8}$ \\
Big FF-firm & 9.1 & 10.9 & 18.2 & 0.0 & 7.5 \\
Small firm & 18.9 & 23.9 & 18.2 & 20.0 & 9.4 \\
Non-profit & 12.9 & 10.9 & 4.5 & 25.3 & 9.4 \\
Other education & 4.9 & - & - & 14.7 & 5.7 \\
Self-employed & 6.3 & 3.3 & 6.1 & 4.0 & 15.1 \\
Sample Size: & $\mathbf{2 8 6}$ & $\mathbf{9 2}$ & $\mathbf{6 6}$ & $\mathbf{7 5}$ & $\mathbf{5 3}$ \\
& & & & & \\
\hline \hline NOTES & & & & &
\end{tabular}

NOTES:

The NSCG sample reflects all women who fit the criteria listed in Section 4.1, but who are childless and within the ages of 26 to 36 . (The median age is 31 , and the 25 th and 75 th percentiles are 28 and 33 . By comparison, in the NSCG mothers sample, among women with only children under age 2, the median age is 33, and the 25th and 75 th percentiles are 30 and 35.) For each sample, the first line(s) reflects the total percentage working in non-family-friendly environments, as defined in the text. The lines that follow reflect the percentage working in each type of work environment, with those classified as non-family-friendly highlighted in bold.

Using these definitions, Table 4 shows the proportion of women working in non-familyfriendly jobs before kids, both overall and by graduate degree. The top panel shows this for

footnote 40 for results when we use this alternate definition. Overall, we find reassuring the general similarity of these two potential definitions. 
a sample of NSCG women who are comparable to our population of mothers, but who are as-yet childless. The bottom panel shows this data for the Harvard longitudinal sample.

Using only the coarser measure of family friendliness, we see that 51 percent of the NSCG women and 57 percent of the Harvard longitudinal sample work in a non-familyfriendly environment. By the more detailed measure, a smaller 48 percent of our Harvard sample work in such an environment before motherhood.

In both datasets and by both measures, we see that family-friendly jobs are least common among MBAs, driven by the high percentage of MBAs who work for (non-familyfriendly) large firms. Thus if work environment has a causal effect on women's labor supply decisions after motherhood, the results in Table 4 provide a potential explanation for the relatively low participation levels among MBAs.

Using the more refined measure for the Harvard sample, however, MBAs are only slightly more likely to be in non-family-friendly jobs than JDs, primarily because of the large number of lawyers who work for the government. Given insight from other sources on the constraints in law, if we were to designate only litigation-heavy government positions as non-family friendly (Swiss and Walker, 1993), and distinguish jobs as legal counsels for big firms as family friendly (Mason and Eckman, 2007), a much lower 36 percent of the Harvard JDs would be categorized as working in an "unfriendly" environment. We do not incorporate this information into our primary measure of family friendliness because we have no similar means to refine our definition for women with other degrees, who tend to work in much less homogenous settings.

\section{Empirical Strategy}

The following section outlines how we will attempt to identify the treatment effect of work environment, given the sources of potential bias discussed in Section 3. 


\subsection{Controlling for Differences in Characteristics}

Exploiting the richness of our two data sources, we begin with the simple approach of assessing whether the observed labor supply differences across women with different graduate degrees can be explained by their characteristics. Rewriting Equation (4),

$$
p\left(h_{i}>0\right)=F\left(\alpha+\sum_{j} \beta_{j} S_{i j}+\gamma_{1} X_{i}+\gamma_{2} \theta_{i}\right),
$$

where $X$ are the factors from the wage and reservation wage equations, and $\theta=(\zeta, \psi)$ are unobserved taste, we first run this specification with no controls, then add $X$, followed by proxies for $\theta$. Our focus is on the degree coefficients, $\beta_{j}$, which reflect the level difference in labor supply between each degree $j$ and MBAs, the excluded category.

The variables $X$ include many common to a married woman's labor supply model, such as her potential wage, number of children, and proxies for spouse's income. ${ }^{30}$ We also include proxies for assets (in the Harvard sample, private school attendance, and in the NSCG, private university attendance and parents' education), and controls to capture variation in childcare costs (census region, and whether a woman lives in the same region in which she was raised, suggesting potential proximity to family). As with many of the other components of $X$, current region may also capture an element of taste, if there exists geographic variation in the social norms on the acceptability of being a working mother (Fogli and Veldkamp, 2008).

The one element of $X$ for which we have very different information in these two datasets is spouse's earnings. In the NSCG we can only observe his labor force status and whether his job requires a BA. In the Harvard data, we instead have estimates of his salary itself,

\footnotetext{
${ }^{30}$ See Appendices A.1 and B.2 for greater detail on how we build estimated wages in the NSCG and Harvard samples, respectively. Following Blau \& Kahn (2007) and Juhn and Murphy (1997), we instrument for wages using predicted wage distribution dummies to address measurement error. For the Harvard data, because we rely on salary estimates as our building block for wages, to absorb any residual effect that may not be captured in our career consultant's estimates, we also control for whether each woman attended a top-10 graduate program and whether she holds more than one graduate degree. In both datasets we also include year-of-graduation (from graduate school) fixed effects, to allow for long-term effects of the economic environment at the time of graduation (Oyer, 2008).
} 
based on his education, occupation, location, and in some instances, firm. ${ }^{31}$

In the Harvard data we also supplement this with detailed information on husbands' education type and quality, including his graduate degree. Along with its influence on his earnings, the latter may also speak to different time constraints that translate into variation in the value of a woman's time at home (Stone and Lovely, 2004). For instance, husbands who are MDs may be on call many nights, and husbands who are MBAs may travel frequently, making each less available for household responsibilities.

We next include controls that may reflect the underlying elements of taste, $\theta$. For instance, we expect educational choices such as undergraduate major, and in the NSCG, type of institution (e.g., liberal arts versus research university), to reflect much about tastes, especially $\psi$. In the Harvard data we can also control for whether a woman had her first child before she started graduate school; choosing a career path after motherhood may signal a strong value associated with the identity of working in that field.

Our detailed information on marriages and spouses in the Harvard data also provide an especially rich set of proxies for $\zeta$. This includes whether a woman changed her name at marriage, and her age difference with her spouse. ${ }^{32}$ Both may speak to differences in the strength of gender norms within the household.

We also include a rich set of controls that are likely to pick up both elements of taste. These include family background, such as race and ethnicity, place of origin, and in the NSCG, citizenship and reason for coming to the US. In the Harvard data we can also control for the dorm in which each woman lived, and whether she played sports. The latter may reflect women whose self-identity is tied more strongly to their athleticism than to their careers, speaking especially to variation in $\psi$.

\footnotetext{
${ }^{31}$ Because we are measuring spouse's earnings after the first child is born, this may reflect career adjustments, especially among men married to women with a high taste for time at home, $\zeta$. We may therefore be "over-controlling" for its effect on women's labor supply, but in turn may be absorbing some of the effect of $\zeta$ on her participation decision.

${ }^{32}$ Goldin and Shim (2004) use the anniversary reports to assess women's surname choices at marriage.
} 
Given our focus on $\beta_{j}$, our hope is that these elements of $X$ and proxies for $\theta$ absorb much of the variation in taste that leads to sorting across graduate degrees. As a check, we can test this directly for the subset of controls observed by the time of college graduation. As Appendix Tables A-5 and A-6 show, undergraduate major is strongly related to a woman's subsequent graduate degree. Many of the other factors are likewise important in predicting this sorting, such as a woman's race, where she grew up, whether she played sports, or the type of institution she attended. In the Harvard data we also find that her dorm is a strong predictor, supporting the interpretation of her choice of dorm as a reflection of taste.

\subsection{Controlling for Pre-Birth Work Environment}

After controlling for $X$ and $\theta$ in Equation (5), if there remain large differences in labor force participation across fields $-\beta_{j}$ remain significantly different from zero - one might interpret this as evidence of systematic variation in other factors, such as work environment. For the Harvard longitudinal sample, we can test for this directly by assessing whether working in a non-family-friendly environment before having children, $n F F_{i 10}$, predicts subsequent labor supply:

$$
p\left(h_{i}>0\right)=F\left(\alpha+\sum_{j} \beta_{j} S_{i j}+\delta n F F_{i 10}+\gamma_{1} X_{i}+\gamma_{2} \theta_{i}\right)
$$

As discussed in Section 3, however, if we cannot fully control for taste, we must be especially wary of any conclusion based on the comparison of women who choose high- and low-cost fields, such as MDs versus MBAs. For that reason, when we run Equation (6) we exclude the two high-cost fields, MDs and PhDs, where we expect the strongest selection on unobserved taste. ${ }^{33}$ Among the remaining women, we also focus our attention on the comparison of JDs and MBAs, where the costs and benefits of each degree are much more similar, both in terms of the length of training, and with respect to the structure of subsequent jobs and their wage trajectories.

Another factor discussed in Section 3 is that because women can sort across jobs, we

\footnotetext{
${ }^{33}$ As noted in footnote 21, we also exclude MDs and PhDs for data reasons.
} 
cannot necessarily interpret $\delta$, the coefficient on pre-birth work environment, $n F F_{i 10}$, as a measure of the causal effect. If women sort across jobs such that those observed in familyfriendly environments before children have systematically higher $\zeta$ and thus lower $h^{*}$, if we cannot fully control for taste, $\delta$ will be attenuated towards zero. (Any measurement error in $n F F_{i 10}$ will likewise attenuate $\delta$ towards zero.) If the opposite sorting predominates, the reverse will hold.

Given how we define family friendliness, women may also sort across jobs based on $\psi$. For instance, non-profit jobs - which may attract high- $\psi$ women - are classified as family friendly. Teaching and government, however, are classified as non-family friendly, and may attract similar women.

To address the bias introduced by this possible sorting, we adopt a control-function strategy. Using the rich data from when our sample were college-age, $C_{i}$, we begin by predicting a woman's choice of pre-birth (post-graduate school) work environment:

$$
n \hat{F} F_{i 10}=P\left(n F F_{i 10}=1 \mid C_{i}, S_{i j}\right) .
$$

We then calculate the residual element of work environment, $n \tilde{F} F_{i 10}=n F F_{i 10}-n \hat{F} F_{i 10}$. To the extent that $C_{i}$ absorb the factors that drive selection across job types, we can interpret $n \tilde{F} F_{i 10}$ as the random element of a woman's pre-birth work environment.

Table 5 reports the coefficients on $C$ in Equation (7) using our Harvard longitudinal sample. To allow for sorting on $\psi$, we include as necessary interactions between individual elements of $C$ and graduate degree $S_{j}$, because the effect of a given control may have varying implications for women in different fields. For instance, majoring in economics could influence MAs in one way and JDs in another. By comparison, if women choose jobs based on their family friendliness alone, and thus sort only on $\zeta$, we would expect the coefficient on a given control to have the same sign for all degrees. ${ }^{34}$

\footnotetext{
${ }^{34}$ This assumes we are capturing women from the same part of the $\zeta$ distribution among all degree groups.
} 
Table 5: Predicting Non-Family-Friendly Work Environment

\begin{tabular}{|c|c|c|c|c|c|}
\hline & All & JD & MBA & MA & None \\
\hline Graduate degree & & $-0.354^{+}$ & - & -0.099 & 0.079 \\
\hline$($ excluded $=$ MBA $)$ & & $(0.182)$ & - & $(0.192)$ & $(0.202)$ \\
\hline \multicolumn{6}{|c|}{ Undergraduate Major: (excluded = liberal arts) } \\
\hline \multirow[t]{2}{*}{ Economics } & & -0.303 & 0.188 & 0.491 & 0.346 \\
\hline & & $(0.197)$ & $(0.165)$ & $(0.300)$ & $(0.312)$ \\
\hline \multirow[t]{2}{*}{ Psychology } & & $-0.517^{*}$ & -0.182 & -0.200 & 0.239 \\
\hline & & $(0.218)$ & $(0.305)$ & $(0.247)$ & $(0.270)$ \\
\hline \multirow[t]{2}{*}{ Other social sciences } & & -0.022 & 0.240 & $-0.324^{*}$ & 0.270 \\
\hline & & $(0.131)$ & $(0.177)$ & $(0.151)$ & $(0.179)$ \\
\hline \multirow[t]{2}{*}{ Science } & & $0.664^{*}$ & 0.029 & -0.112 & - \\
\hline & & $(0.300)$ & $(0.358)$ & $(0.245)$ & - \\
\hline \multirow{2}{*}{\multicolumn{2}{|c|}{ Played sports in college }} & $0.353^{* *}$ & -0.109 & 0.171 & -0.243 \\
\hline & & $(0.128)$ & $(0.131)$ & $(0.136)$ & $(0.199)$ \\
\hline \multicolumn{6}{|c|}{ Race: (excluded = Caucasian) } \\
\hline \multirow{2}{*}{\multicolumn{2}{|c|}{ Asian }} & $0.585^{* *}$ & 0.079 & 0.074 & -0.072 \\
\hline & & $(0.169)$ & $(0.192)$ & $(0.248)$ & $(0.409)$ \\
\hline \multirow[t]{2}{*}{ Other minority } & 0.200 & & & & \\
\hline & $(0.157)$ & & & & \\
\hline \multirow{2}{*}{\multicolumn{2}{|c|}{ Private high school }} & 0.093 & -0.188 & -0.188 & $-0.334^{+}$ \\
\hline & & $(0.118)$ & $(0.141)$ & $(0.135)$ & $(0.173)$ \\
\hline \multicolumn{6}{|c|}{ Region in High School: (excluded = D.C. area) } \\
\hline \multirow[t]{2}{*}{ Northeast } & -0.071 & & & & \\
\hline & $(0.128)$ & & & & \\
\hline \multirow[t]{2}{*}{ Mid-Atlantic } & $-0.226^{+}$ & & & & \\
\hline & $(0.133)$ & & & & \\
\hline \multirow[t]{2}{*}{ Midwest } & & $-0.439^{*}$ & -0.418 & 0.200 & -0.169 \\
\hline & & $(0.196)$ & $(0.271)$ & $(0.285)$ & $(0.242)$ \\
\hline \multirow[t]{2}{*}{ West (excluding CA) } & & -0.366 & -0.344 & 0.625 & $0.966^{*}$ \\
\hline & & $(0.310)$ & $(0.398)$ & $(0.403)$ & $(0.399)$ \\
\hline \multirow[t]{2}{*}{ California } & & $0.429^{+}$ & -0.156 & -0.242 & 0.163 \\
\hline & & $(0.231)$ & $(0.230)$ & $(0.234)$ & $(0.266)$ \\
\hline \multirow[t]{2}{*}{ Big city } & 0.077 & & & & \\
\hline & $(0.088)$ & & & & \\
\hline \multirow[t]{2}{*}{ Low-density state } & & $0.311^{+}$ & 0.057 & -0.105 & -0.413 \\
\hline & & $(0.177)$ & $(0.273)$ & $(0.291)$ & $(0.293)$ \\
\hline
\end{tabular}

\section{NOTES:}

Results reflect coefficients from a single OLS regression predicting the probability of working in a non-family friendly environment 10 years after college, given one's graduate education and factors observed at college graduation. (Also included, but not shown here, include undergraduate dorm and growing up in the south or outside of the US.) The first column reports the marginal effect for factors that are not interacted by degree; the following four columns report the coefficient on the interaction term between the given control and each graduate degree, included only in those instances in which at least one interaction term is individually significant (or close at standard levels), and significantly different from another interaction term. The sample included are the 286 women in the Harvard longitudinal sample. The $R^{2}$ and adjusted $R^{2}$ are 0.38 and 0.17 , respectively. Statistical significance is indicated by ${ }^{+}$at $10 \%,{ }^{*}$ at $5 \%$, and ${ }^{* *}$ at $1 \%$. 
Table 5 shows that the factors observable at college graduation are strongly related to the types of jobs women hold 10 years later. For instance, undergraduate major has a strong relationship with whether a woman subsequently works in a family-friendly job, although the direction of sorting varies across degrees. Race, place of origin, and sports participation are also closely related, again with varying effects across groups. By comparison, the effect of undergraduate dorms is surprisingly consistent across degrees, and is a good predictor of the family-friendliness of women's pre-birth jobs.

One might worry, however, that these college-level variables are more likely to pick up variation in $\psi$ than in $\zeta$. Do 19- or 22-year old women really know if they will want to take time off when they have children? Our results suggest that they do. If we regress the residual element of work environment, $n \tilde{F} F_{i 10}$, on factors that occur after graduation but before the 10th-year job, these controls provide little additional explanatory power, even though many are strongly related to subsequent labor supply after motherhood.

Furthermore, we find that $C$ can predict who will take her husband's name at marriage, which we consider a proxy for $\zeta$. In particular, it is the information on undergraduate dorm that provides this power. Combining this with our finding that the effect of dorm choice on $n F F_{i 10}$ is almost identical across degrees, this suggests that the element of taste that drives a woman's choice of dorm at the age of 19 is strongly correlated with $\zeta$.

Given this decomposition of observed pre-birth work environment, we then rerun Equation (6), replacing $n F F_{i 10}$ with the predicted value and the residual, $n \hat{F} F_{i 10}$ and $n \tilde{F} F_{i 10}$. In this control-function regression, to the extent that the college-level factors $C_{i}$ absorb selection across job types, the coefficient on $n \tilde{F} F_{i 10}$ should give us the causal effect of work environment, and the difference between the coefficient on $n \tilde{F} F_{i 10}$ and $n \hat{F} F_{i 10}$ will give us the direction of the bias created by this selection. Furthermore, any attenuation in the graduate degree coefficients after controlling for this admittedly blunt measure of work environment, will suggest that variation in family friendliness across fields helps drive the overall variation in labor supply. 


\section{Results}

Table 6 reports the marginal effects associated with the degree coefficients, $\beta_{j}$, when we run Equation (5) on the NSCG and Harvard samples (top and bottom panels, respectively). In each panel, Line (1) reports the results before including controls, Line (2) the results after including only $X$, and Line (3) the fully-controlled specification. The columns between the marginals report whether the differences between adjacent graduate programs are statistically significant. Appendix Table A-7 reports the marginals for the controls.

Table 6: Differences in Probability Working by Graduate Degree

\begin{tabular}{|c|c|c|c|c|c|c|c|c|}
\hline & & MD & & PhD & JD & MA & None & $\bar{l}^{2}$ \\
\hline \multicolumn{9}{|c|}{ NSCG Sample } \\
\hline (1) & Uncontrolled & $\begin{array}{c}0.184^{* *} \\
(0.028)\end{array}$ & ** & $\begin{array}{l}0.085^{*} \\
(0.038)\end{array}$ & $\begin{array}{c}0.027 \\
(0.048)\end{array}$ & $\begin{array}{l}-0.005 \\
(0.036)\end{array}$ & - & 0.02 \\
\hline$(2)$ & $+\mathrm{Xs}_{\mathrm{s}}$ & $\begin{array}{c}0.172^{* *} \\
(0.025)\end{array}$ & * & $\begin{array}{c}0.104^{* *} \\
(0.035)\end{array}$ & $\begin{array}{c}0.051 \\
(0.044)\end{array}$ & $\begin{array}{l}-0.003 \\
(0.038)\end{array}$ & - & 0.10 \\
\hline (3) & + Proxies for $\theta$ & $\begin{array}{c}0.152^{* *} \\
(0.032)\end{array}$ & & $\begin{array}{l}0.104^{* *} \\
(0.037)\end{array}$ & $\begin{array}{c}0.047 \\
(0.047)\end{array}$ & $\begin{array}{l}-0.007 \\
(0.041)\end{array}$ & - & 0.14 \\
\hline \multicolumn{9}{|c|}{ Harvard Sample } \\
\hline (1) & Uncontrolled & $\begin{array}{c}0.205^{* *} \\
(0.027)\end{array}$ & $*$ & $\begin{array}{l}0.114^{* *} \\
(0.036)\end{array}$ & $\begin{array}{cc}+ & 0.049 \\
& (0.039)\end{array}$ & $\begin{array}{c}0.011 \\
(0.043)\end{array}$ & $\begin{array}{l}-0.025 \\
(0.045)\end{array}$ & 0.05 \\
\hline$(2)$ & $+\mathrm{Xs}$ & $\begin{array}{c}0.172^{* *} \\
(0.026)\end{array}$ & + & $\begin{array}{l}0.090^{*} \\
(0.042)\end{array}$ & $\begin{array}{l}0.069^{+} \\
(0.038)\end{array}$ & $\begin{array}{c}0.044 \\
(0.047)\end{array}$ & $\begin{array}{c}0.007 \\
(0.073)\end{array}$ & 0.21 \\
\hline$(3)$ & + Proxies for $\theta$ & $\begin{array}{c}0.158^{* *} \\
(0.025)\end{array}$ & $*$ & $\begin{array}{c}0.066 \\
(0.045)\end{array}$ & $\begin{array}{c}0.046 \\
(0.040)\end{array}$ & $\begin{array}{c}0.016 \\
(0.052)\end{array}$ & $\begin{array}{l}-0.029 \\
(0.081)\end{array}$ & 0.28 \\
\hline
\end{tabular}

NOTES:

Each line reflects the results from a different probit regression of labor force participation after motherhood, including an increasing number of controls, with the excluded category MBAs. The values listed are the marginal effects associated with the given degree coefficient, $\beta_{j}$, from Equation (5). The first line reports results when we control only for graduate degree. The second and third lines reflect the results when we control for the observable elements of the wage equation $(X)$ and proxies for the unobservable elements $(\theta)$. (Lines (2) and (3) are estimated via instrumental variables; see footnote 30 for more detail.) See Appendix Table A-7 for a full listing of the controls included in the regressions reported in Lines (2) and (3), as well as the marginal coefficients for a subset of these controls. The columns between the coefficients in this table report whether the differences between adjacent graduate programs are statistically significant. The last column reports the pseudo- $\mathrm{R}^{2}$ when we run the probit without instrumenting for own wage. Significance levels marked as ${ }^{+}$(significant at $\left.10 \%\right),{ }^{*}$ (at 5\%), and ** (at 1\%).

As with the raw data, the results in Lines (1) are very similar in the two samples. ${ }^{35}$ In each we see, for instance, that MDs work appreciably more than PhDs, and both MDs and

\footnotetext{
${ }^{35}$ Whereas the labor force participation rates for MDs, PhDs, and JDs are almost identical in these two samples, in the Harvard sample MBAs are slightly less likely to work than MBAs in the NSCG, creating a small level difference in the degree marginals reported here.
} 
PhDs work more than MBAs. But we cannot reject that MBAs are as likely to work as JDs, MAs, and in the Harvard sample, those with no graduate degree.

As the results in Lines (2) and Appendix Table A-7 demonstrate, the elements of $X$ are highly correlated with labor supply in the predicted way, and the $R^{2}$ s rise appreciably with their addition. ${ }^{36}$ Yet including these controls does little to narrow the difference in labor supply across graduate degrees. In both samples the coefficient on JDs in fact rise - in part because they have more children than MBAs - thus augmenting the difference between these two fields.

When we include the proxies for taste, we find that many are strongly related to labor force participation. For instance, in the Harvard data, women who begin graduate school after having children - a proxy for $\psi$ - are 10 percentage points more likely to remain working. We also see that those who change their last name at marriage are instead 11 percentage points more likely to quit. Because MBAs are by far the most likely to do so, this in part helps explain their lower participation.

Despite the power of these controls in predicting work patterns, and the resulting attenuation of most of the degree coefficients towards zero, the changes are fairly small. In combination, a comparison of Lines (1) and (3) in both panels show that persistent differences in labor supply remain, even after controlling for these rich sets of individualspecific factors. ${ }^{37}$

Table 7 reports the results of Equation (6), where we rerun the fully-controlled specification on the Harvard longitudinal sample, now controlling directly for pre-birth work environment. Column (1) lists the degree-specific coefficients, $\beta_{j}$, for this subset of women before including work environment, Column (2) reports the results when we control for the

\footnotetext{
${ }^{36}$ The $R^{2}$ is higher in the Harvard results, in part because of the richer data on spouse's earnings, but also because of the greater sample homogeneity. Even in specifications in which we include only those controls that are observed in both datasets, the $R^{2} \mathrm{~s}$ are consistently higher in the Harvard regressions.

${ }^{37}$ The results for PhDs vary in the two datasets primarily because of the large proportion of science-related PhDs among women in the NSCG.
} 
Table 7: Effect of Pre-Birth Work Environment

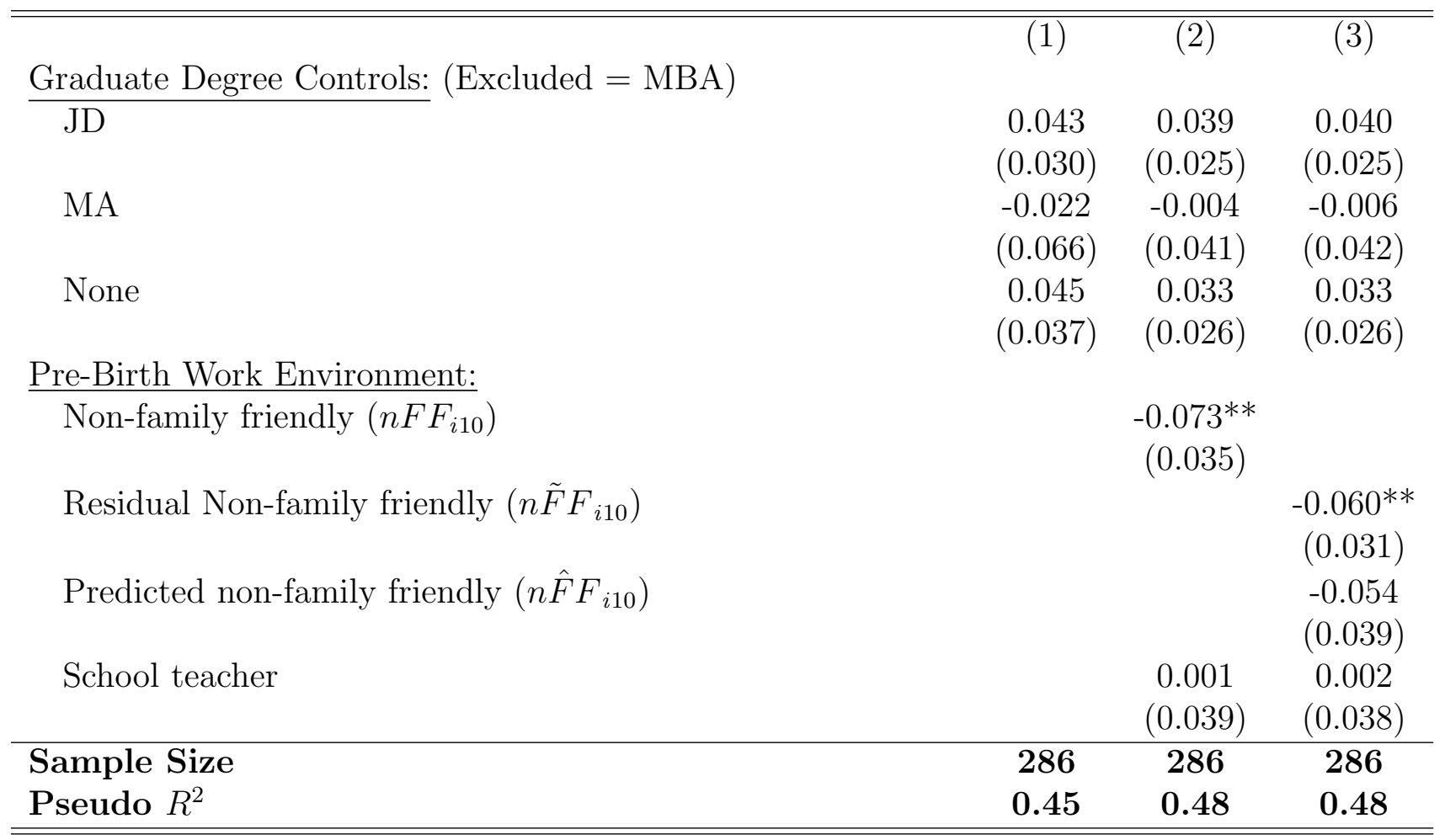

NOTES:

Each column reflects a different specification predicting labor force participation after children (15 years after college graduation), reporting results before and after controlling for pre-birth work environment. Reported values reflect the marginal effect calculated from a probit regression; we do not use the IV specification described in the notes to Table 6 because doing so has no effect on the results. See footnote 27 for why we separately distinguish teachers from those in other non-family-friendly environments. Because wages may be systematically lower in family-friendly jobs, we also run regressions which control for wages in a more flexible way; this has no effect on the results reported here. Standard errors reported in parentheses; significance levels marked as ${ }^{+}$significant at $10 \%$; ${ }^{*}$ at $5 \%$; ${ }^{* *}$ at $1 \%$.

observed value, $n F F_{i 10}$, and Column (3) reports the control-function results.

As the results in Columns (2) and (3) show, working in a non-family-friendly environment before having children is significantly associated with a woman's labor supply five years later. The small and insignificant difference between the coefficients on $n \hat{F} F_{i 10}$ and $n \tilde{F} F_{i 10}$ in Column (3), combined with the evidence in Section 5 that $n \tilde{F} F_{i 10}$ is largely orthogonal to taste, suggest that sorting across work environments creates little to no bias in the estimated effect of work environment. And the coefficients on $n F F_{i 10}$ in Column (2) and on $n \tilde{F} F_{i 10}$ in Column (3) are accordingly very similar: women who work in a nonfamily friendly environment are 6 to 7 percentage points less likely to continue working after 
motherhood. ${ }^{38}$

\section{Interpreting Our Results}

Although the results in Table 7 make it clear that working in a non-family-friendly environment influences labor supply after motherhood, it is less clear that it can explain work patterns observed by graduate degree. As discussed in Section 5, if variation in work environment is a driving factor, controlling for it directly should attenuate the degree coefficients towards zero. ${ }^{39}$ As shown in Table 7 , we do find that the coefficients for JDs and women with no graduate degree are somewhat attenuated. ${ }^{40}$ But notice that although the alternative definition discussed at the end of Section 4.4 suggests that fewer Harvard JDs are in non-family-friendly jobs, by our main definition used in Table 7, JDs are almost as likely to work in such environments as MBAs.

Since we observe that JDs are less likely to quit, is this because their "non-familyfriendly" jobs are less unfriendly than the jobs held by MBAs? For instance, among the Harvard women who initially worked in non-family-friendly jobs, we see in the top panel of Table 8 that JDs and MAs are much more likely to remain in such an environment than either MBAs or women with no degree.

\footnotetext{
${ }^{38}$ One might ask whether these results reflect variation in the production functions of jobs across industries. Are certain jobs by their nature easier for women to pair with motherhood? We do not include industry fixed effects for two reasons: (1) controlling for industry may also capture systematic variation in work norms and mores (e.g., variation in the strength of the "old boys" network), which may encompass part of a job's family friendliness, and (2) we do not believe that production functions are a fixed characteristic. (Consider the shift in the structure of many medical specialties over the last 30 years, and its influence on the capacity for MDs to work part-time.) If, however, one splits the sample of women who worked in large for-profit firms into 7 broad industry groups, within each, the proportion who remain working is higher among those who worked for family-friendly firms. For instance, in banking, 88 percent of those who worked in family-friendly firms remain working, compared to only 67 percent of those previously in non-family-friendly firms.

${ }^{39}$ In comparison to the coefficient in Table 6, the initial coefficient for MAs in Table 7 is negative. (This may reflect the strong positive selection into the longitudinal sample evident for MBAs - see Appendix Section C.) Since, by our definition, these MAs are less likely than MBAs to work in non-family-friendly jobs, we should instead expect their coefficient to become more negative. Although Table 7 instead shows that the coefficient moves towards zero, the standard errors are large in comparison to the point estimates.

${ }^{40}$ Using the alternate definition of family friendliness discussed at the end of Section 4.4, the coefficients for JDs and MAs are instead 0.030 (s.e. 0.023) and -0.013 (s.e. 0.045), and the effect of work environment is 6 to 9 percentage points. Likewise, following the alternate definition from footnote 29, the coefficients for JDs and women with no graduate degree are attenuated to 0.034 (s.e. 0.024 ) and 0.026 (s.e. 0.024). Lastly, if we use the coarser measure that excludes firm-specific information, the estimated effect of work environment is 3 to 4 percentage points.
} 
Table 8: Work Environment Before and After Children

\begin{tabular}{|c|c|c|c|c|c|}
\hline & All & JD & MBA & MA & None \\
\hline \multicolumn{6}{|c|}{ Post-Children Work Environment: } \\
\hline \multicolumn{6}{|c|}{ Working in a non-family-friendly position at 10th: } \\
\hline$\%$ Non-family friendly & 45.6 & 55.3 & 35.3 & 33.3 & 53.6 \\
\hline$\%$ Family friendly & 28.7 & 27.7 & 29.4 & 40.7 & 17.9 \\
\hline$\%$ At home & 25.7 & 17.0 & 35.3 & 25.9 & 28.6 \\
\hline \multicolumn{6}{|c|}{ Working in a family-friendly position at 10th: } \\
\hline$\%$ Non-family friendly & 17.2 & 15.9 & 23.3 & 19.1 & 8.3 \\
\hline$\%$ Family friendly & 68.3 & 68.2 & 60.0 & 66.0 & 83.3 \\
\hline$\%$ At home & 14.5 & 15.9 & 16.7 & 14.9 & 8.3 \\
\hline \multicolumn{6}{|c|}{ Work Setting: (All women who remain working) } \\
\hline \multicolumn{6}{|c|}{ 10th Year: } \\
\hline Big non-FF firm & 32.4 & 32.9 & 44.7 & 18.3 & 38.1 \\
\hline Government & 9.8 & 18.4 & 2.1 & 8.3 & 9.8 \\
\hline School teacher & 2.7 & - & - & 6.7 & 4.8 \\
\hline Big FF firm & 10.7 & 11.8 & 23.4 & 0.0 & 9.5 \\
\hline Small firm & 18.7 & 21.1 & 19.1 & 21.7 & 9.5 \\
\hline Non-profit & 14.7 & 11.8 & 6.4 & 26.7 & 11.9 \\
\hline Other education & 4.9 & - & - & 13.3 & 7.1 \\
\hline Self-employed & 6.2 & 3.9 & 4.3 & 5.0 & 14.3 \\
\hline \multicolumn{6}{|l|}{ 15th Year: } \\
\hline Big non-FF firm & 28.9 & 30.3 & 38.3 & 16.7 & 33.3 \\
\hline Government & 7.1 & 13.2 & 2.1 & 6.7 & 2.4 \\
\hline School teacher & 2.7 & - & - & 6.7 & 4.8 \\
\hline Big FF firm & 6.2 & 7.9 & 10.6 & 1.7 & 4.8 \\
\hline Small firm & 12.4 & 11.8 & 21.3 & 6.7 & 11.9 \\
\hline Non-profit & 21.8 & 26.3 & 14.9 & 25.0 & 16.7 \\
\hline Other education & 5.8 & - & - & 16.7 & 7.1 \\
\hline Self-employed & 15.1 & 10.5 & 12.8 & 20.0 & 19.0 \\
\hline
\end{tabular}

\section{NOTES:}

Data for the Harvard longitudinal sample, using the more detailed measure of family friendliness. In the listing of detailed work environments, those classified as non-family-friendly are highlighted in bold.

If we return to the labor supply data for NSCG mothers used in Table 3, we do see evidence that non-family-friendly environments are especially "unfriendly" for MBAs. For instance, looking further down in the hours distribution, we see that the MBAs in big firms their most common work setting - are the only group who remain working 40 hours per week at the 20th percentile, and full-time at the 15 th. Overall we see a much smaller proportion of MBAs working part-time: only 23 percent, compared to 32 percent of MAs and JDs. 
This raises the question: Do we observe fewer MBA mothers working part-time because fewer part-time options exist, or because the career consequences of going part-time are especially high? Some evidence from the NSCG suggests the former. We see that 14 percent of MBA mothers are working in jobs unrelated to their education, compared to at most 5 percent in all other degrees. ${ }^{41}$ Among these MBAs, 53 percent work part-time, compared to 17 percent among the remainder, suggesting the necessity to leave "MBA-type" jobs in order to be able to work part-time. In their study of graduates from Harvard's medical, law, and business schools, Swiss and Walker (1993) likewise report that many women who left the labor force - especially MBAs - would have preferred to work part-time, but were not offered the option by their pre-birth employer.

Evidence for the Harvard longitudinal sample likewise suggests that JDs face relatively more family-friendly options than MBAs. Returning to the top panel of Table 8, among women who were working in non-family-friendly environments before kids, we see that MBAs and women with no graduate degree are more likely to quit than to switch to a family-friendly job, whereas the reverse holds for JDs and MAs. ${ }^{42}$ (By comparison, among those who were working in family-friendly jobs before motherhood, MBAs are no more likely to quit.) Among those who remain working, the bottom panel of Table 8 shows a large shift towards non-profit jobs and self-employment. ${ }^{43,44}$

Other sources also suggest that among women working in jobs with formal "workfamily" policies, MBAs face the highest career repercussions for using these policies. For instance, among workers in a financial services firm, Blair-Loy and Wharton (2002) report high levels of concern over the harmful career effects of using available work-family policies.

\footnotetext{
${ }^{41}$ This difference is significant at the 1 percent level. This same pattern does not hold among women who have not yet had children.

${ }^{42}$ This difference between the JDs and MBAs is significant at the 10 percent level.

${ }^{43}$ This shift towards self-employment supports past research suggesting that women enter self-employment as a means to balance household responsibilities with a maintained labor force presence (Connolly, 1992; Hundley, 2000).

${ }^{44}$ Although these results show only a small decrease in the proportion of JDs working at large non-familyfriendly firms, much of this is driven by women working as special counsels. If we were to categorize these as family-friendly jobs per Mason and Eckman (2007), the proportion of JDs working in a non-family-friendly firm would shift from 30 percent before motherhood to 24 percent afterwards, and the proportion working in family-friendly positions would stay even at 14 percent. This suggests that Mason and Eckman are correct.
} 
By comparison, Wood et al. (1993) find that the use of such policies among law school graduates bore no relationship with future promotions.

In a survey of highly educated women, Hewlett et al. (2005) likewise find evidence that MBAs fear greater career penalties for using these policies than women in other fields. Table 9, which shows a subset of their results, reports that women in business, and especially those in finance, perceive greater barriers to using available work-family policies, and takeup rates are correspondingly lower. These results are especially telling for our sample of Harvard women, since 26 percent of the MBAs in the longitudinal sample work in finance or banking before they have children.

Table 9: Evidence on Variation in Work Environment

\begin{tabular}{|c|c|c|c|c|c|}
\hline & Medicine & Academia & Law & Business & $\begin{array}{c}\text { Finance \& } \\
\text { Banking }\end{array}$ \\
\hline \multicolumn{6}{|c|}{ Variation in Family-Friendly Environment: } \\
\hline \multicolumn{6}{|c|}{ Perceived Barriers to Using Available Work Balance Options: (\%) } \\
\hline Reduced Hours & 30 & 36 & 25 & 42 & 56 \\
\hline Flexible Hours & 29 & 23 & 22 & 33 & 45 \\
\hline Part-time senior positions & 35 & 32 & 46 & 36 & 75 \\
\hline Unspoken rule that those who & 24 & 20 & 24 & 32 & 41 \\
\hline used available options would & not be prom & ted & & & \\
\hline \multicolumn{6}{|c|}{ Labor Supply Choices to Accommodate Work Balance: (\%) } \\
\hline Worked part-time & 37 & 32 & 30 & 26 & 12 \\
\hline Worked reduced hours $(>\mathrm{PT})$ & 38 & 25 & 27 & 26 & 30 \\
\hline
\end{tabular}

NOTES:

Data from Hewlett, Luce, Shiller, and Southwell (2005), from a survey of 2,500 "highly qualified" US women - those with a graduate degree or a college degree with honors. The categories by which they group women reflects the makeup of the committee sponsoring the survey, including representatives from Goldman Sachs, Lehman Brothers, and Ernst \& Young. From the data reported we cannot determine if differences across columns are statistically significant.

All told, this evidence suggests that MBAs work in systematically less family-friendly environments, which may help explain their lower labor force participation after motherhood. Yet this begs a final question: for those MBAs who ultimately quit, why did they complete an MBA in the first place? ${ }^{45}$

\footnotetext{
${ }^{45}$ Note that these women may not leave the labor force for long. Goldin and Katz (2008) report that the mean length of time off for mothers in their 1990 cohort was only 19 months, although longer among MBAs than among other women. Yet Bertrand et al. (2010) find enormous financial penalties for any gaps for MBAs, much larger than the corresponding penalties for JDs. Thus this only increases the puzzle of why
} 
One possible explanation is that these women had the least information about the family friendliness of their intended field at the time they applied to graduate school. By our estimate, however, MBAs took the most time off before returning to school - approximately 4 years in comparison to 2 for JDs. This greater level of work experience suggests that MBAs should instead have had better information on the family-friendliness of their intended field. ${ }^{46}$

An alternative possibility is that women who chose an MBA were systematically too optimistic about how quickly the field would change between the time when they chose their graduate program, and the time when they had their first child, on average 7 years later. Even if these women understood the current level of family friendliness within the business world, they may have expected it to get better over the following years. ${ }^{47}$ This far in advance, it is also possible that many were not thinking about this at all. Thus the investment decisions that look questionable ex post may have been rational ex ante.

\section{Conclusion}

Our results provide insight into the labor supply decisions of highly educated women, many of whom delayed fertility as they completed additional schooling and established their careers. Yet despite the large opportunity cost of doing so, we see that a substantial proportion leave the labor force, at least temporarily, at the transition into motherhood.

More strikingly, we find that this propensity varies dramatically across career paths, and is remarkably consistent across two different populations of women. Furthermore, this difference remains, even when we take into consideration variation in very rich sets of observable characteristics, many of which we expect to be correlated with unobservable elements of taste important in both the labor supply decision and selection across careers. Lastly, we MBAs are more likely to quit.

${ }^{46}$ Another possibility is that MBAs were especially likely to underestimate their taste for time at home once they had children. If women learn about their value of $\zeta$ as they age, however, MBAs should instead have had the most accurate information about their taste when they made their choice across fields.

${ }^{47}$ MBAs need not have been more optimistic than women choosing other fields. If the family friendliness of the business world progressed more slowly over this period than in other fields, they may simply have been more incorrect in their expectations. 
find that women who worked in non-family-friendly jobs before they had children are 6 to 7 percentage points less likely to remain working after motherhood.

We find these results suggestive that a woman's work environment plays a causal role in "pushing" her out of the labor force at motherhood. Our results also suggest that variation in family friendliness across high-education careers helps explain variation in female labor force participation - that the raw differences in the proportion of mothers who work in these high-powered professions speaks at least in part to treatment, and not solely to selection.

Comparing the outcomes for JDs and MBAs, evidence suggests that women in law face a larger set of family-friendly job alternatives, and that the career consequences of using available family-friendly options are most costly in the business world. This is clearly an area where more research needs to be done to address the influence of work environment on mother's labor supply decisions. Our results suggest, however, that with improved workfamily policies and changes in social norms, a smaller proportion of women would exit, or "opt out" of, the labor force at motherhood. 


\section{References}

[1] American Medical Association, Center for Health Policy Research. 2002. Physician Socioeconomic Statistics, 2000-2002.

[2] Anderson, Deborah J., Melissa Binder, and Kate Krause. 2003. The Motherhood Wage Penalty Revisited: Experience, Heterogeneity, Work Effort, and Work-Schedule Flexibility. Industrial and Labor Relations Review, Vol. 56(2): 273-294.

[3] Arthur, Michelle M. and Alison Cook. 2003. The Relationship Between Work-Family Human Resource Practices and Firm Profitability: A Multi-theoretic Perspective. Research in personnel and human resource management, Vol. 22: 219-252.

[4] Arthur, Michelle M. and Alison Cook. 2004. Taking Stock of Work-Family Initiatives: How Announcements of "Family-Friendly" Human Resource Decisions Affect Shareholder Value. Industrial and Labor Relations Review, 57(4): 599-613.

[5] Baker, Joe G. 2002. The Influx of Women into Legal Professions: An Economic Analysis. Monthly Labor Review, August 2002: 14-24.

[6] Batt, Rosemary and P. Monique Valcour. 2003. Human Resources Practices as Predictors of Work-Family Outcomes and Employee Turnover. Industrial Relations, 42(2): 189-220.

[7] Belkin, Lisa. 2003. The Opt-Out Revolution. New York Times, October 26, 2003.

[8] Berg, Peter, Arne L. Kalleberg, and Eileen Appelbaum. 2003. Balancing Work and Family: The Role of High-Commitment Environments. Industrial Relations, 42(2): 16888.

[9] Berger, Joseph. 2007. Exploring Ways to Shorten the Ascent to a PhD. New York Times, October 3, 2007.

[10] Bertrand, Marianne, Claudia Goldin, and Lawrence F. Katz. 2010. Dynamics of the Gender Gap for Young Professionals in the Financial and Corporate Sectors, American Economic Journal: Applied Economics, 2(3): 228-255.

[11] Blair-Loy, Mary and Amy S. Wharton. 2002. Employee's Use of Work-Family Policies and the Workplace Social Context. Social Forces, 80(3): 813-845.

[12] Blair-Loy, Mary and Amy S. Wharton. 2004. Organizational Committment and Constraints on Work-Family Policy Use: Corporate Flexibility Policies in a Global Firm. Sociological Perspectives, 47(3): 243-267.

[13] Blau, Francine D., and Lawrence M. Kahn. 2007. Changes in the Labor Supply Behavior of Married Women: 1980-2000. Journal of Labor Economics, 25(3): 393-438.

[14] Boulis, Ann. 2004. The Evolution of Gender and Motherhood in Contemporary Medicine. Annals of the American Academy of Political and Social Science, 596: 172206. 
[15] Boushey, Heather. 2005. Are Women Opting Out? Debunking the Myth. Center for Economic and Policy Research Briefing Paper.

[16] Clifton, Thomas J. and Edward Shepart. 2004. Work and Family Programs and Productivity: Estimates Applying a Production Function Model. International Journal of Manpower, 25(7-8): 714-728.

[17] Connelly, Rachel. 1992. Self-Employment and Providing Child Care. Demography, Vol. 29(1): 17-29.

[18] Drago, Robert and Douglas Hyatt. 2003. Symposium: The Effect of Work-Family Policies on Employees and Employers. Industrial Relations, 42(2): 139-144.

[19] Drago, Robert, David Costanza, Robert Caplan, Tanya Brubaker, Darnell Cloud, Naomi Harris, Russell Kashian, and T. Lynn Riggs. 2001. The Willingness-to-Pay for Work/Family Policies: A Study of Teachers. Industrial and Labor Relations Review, Vol. 55(1): 22-41.

[20] Eaton, Susan C. 2003. If You Can Use Them: Flexibility Policies, Organziational Commitment, and Perceived Performance. Industrial Relations, 42(2): 145-167.

[21] Fernandez, Raquel and Alessandra Fogli. 2009. Culture: An Empirical Investigation of Beliefs, Work and Fertility. American Economic Journal: Macroeconomics, 1(1): 146177.

[22] Fogli, Alessandra and Laura Veldkamp. 2008. Nature or Nurture? Learning and the Geography of Female Labor Force Participation. NBER Working Paper \#14097.

[23] Fortin, Nicole M. 2005. Gender Role Attitudes and Women's Labour Market Outcomes Across OECD countries. Oxford Review of Economic Policy, 21: 416-438.

[24] Goldin, Claudia. 2006. The Quiet Revolution that Transformed Women's Employment, Education and Family. American Economic Review, 96(2): 1-21.

[25] Goldin, Claudia and Lawrence F. Katz. 2008. Transitions: Career and Family Life Cycles of the Educational Elite. American Economic Review: Papers $\&$ Proceedings,98(2): 363369.

[26] Goldin, Claudia and Maria Shim. 2004. Making a Name: Women's Surnames at Marriage and Beyond. Journal of Economic Perspectives, 18 (Spring): 143-60.

[27] Heckman, James. 1974. Shadow Prices, Market Wages, and Labor Supply. Econometrica, 42(4): 679-694.

[28] Hewlett, Sylvia Ann, Carolyn Buck Luce, Peggy Shiller, and Sandra Southwell. 2005. The Hidden Brain Drain: Off-Ramps and On-Ramps in Womens Careers. Harvard Business Review Research Report, March 2005.

[29] Hochschild, Arlie. 1997. The Time Bind: When Work Becomes Home and Home Becomes Work. New York: Metropolitan Books. 
[30] Hundley, Greg. 2000. Male/Female Earnings Differences in Self-Employment: The Effects of Marriage, Children, and the Household Division of Labor. Industrial and Labor Relations Review, Vol. 54(1): 95-114.

[31] Johnson, Nancy Brown and Keith G. Provan. 1995. The Relationship Between Work/Family Benefits and Earnings: A Test of Competing Predictions. Journal of Socio-Economics, 24(4): 571-584.

[32] Joint Economic Committee (Majority Staff). 2008. Equality in Job Loss: Women are Increasingly Vulnerable to Layoffs During Recessions. July 22, 2008.

[33] Juhn, Chinhui and Kevin M. Murphy. 1997. Wage Inequality and Family Labor Supply. Journal of Labor Economics, 55(1, part 1): 72-97.

[34] Landers, Renee M., James B. Rebitzer, and Lowell J. Taylor, 1996. Rat Race Redux: Adverse Selection in the Determination of Work Hours in Law Firms, American Economic Review, 86(3): 329-348.

[35] Leonhardt, David. 2009. Economic Scene: Financial Careers Come at a Cost to Families. New York Times, May 27, 2009.

[36] Mason, Mary Ann and Eve Mason Eckman. 2007. Interrupted Work Careers: Depreciation and Restoration of Human Capital. Mothers on the Fast Track: How a New Generation Can Balance Family and Careers. Oxford University Press.

[37] Mincer, Jacob and Haim Ofek. 1982. Interrupted Work Careers: Depreciation and Restoration of Human Capital. The Journal of Human Resources, 17(1): 3-24.

[38] Mosisa, Abraham and Steve Hippie. 2006. Trends in Labor Force Participation in the United States. Monthly Labor Review, October: 35-57.

[39] Nielsen, Helena S., Marianne Simonsen, and Mette Verner. 2004. Does the Gap in Family-friendly Policies Drive the Family Gap? Scandinavian Journal of Economics, 106(4): 721-744.

[40] Oyer, Paul. 2008. The Making of an Investment Banker: Macroeconomic Shocks, Career Choice, and Lifetime Income. Journal of Finance, 63(6): 2601-2628.

[41] Russo, Eugene. 2004. Fast Track: PhDs. Nature, Vol 431, Sept. 16th, 2004.

[42] Polachek, Solomon William. 1977. "Occupational Segregation Among Women: Theory, Evidence, and A Prognosis", in Women in the Labor Market, Cynthia B. Lloyd, Emily S. Andrews, and Curtis L. Gilroy, Eds. Columnia University Press.

[43] Stone, Pamela and Meg Lovejoy. 2004. Fast-Track Women and the "Choice" to Stay Home. Annals of the American Academy of Political and Social Science, 596: 62-83.

[44] Swiss, Deborah J., and Judith P. Walker. 1993. Women and the work/family dilemma: how today's professional women are finding solutions. New York: J. Wiley.

[45] Tomlinson, Jennifer. 2004. Perceptions and Negotiations of the "Business Case" for Flexible Careers and the Integration of Part-Time Work. Women in Management Review, 19(8): 413-420. 
[46] Wallis, Claudia. 2004. The Case for Staying Home. Time Magazine, March 22, 2004.

[47] Wax, Amy L. 2004. Family-Friendly Workplace Reform: Prospects for Change. Annals of the American Academy of Political and Social Science, 596: 36-61.

[48] Wood, Robert G., Mary E. Corcoran, and Paul N. Courant. 1993. Pay Differences Among the Highly Paid: The Male-Female Earnings Gap in Lawyers' Salaries. Journal of Labor Economics, 11(3): 417-441. 


\section{Data Appendix}

\section{A NSCG Data}

The 2003 wave of the National Survey of College Graduates captures a sample of 100,402 US residents who held at least a bachelors degree as of April 1st, 2000, who lived in the US or its territories at both that time and on October 1st, 2003, and who were age 76 and under as of the latter point. Of these, 43,185, or 49.4 percent (weighted), are women. Given our focus on the highly educated, we limit this sample to those who have at least a masters degree (35 percent).

To provide a more homogeneous sample, we also limit ourselves to those who never attended a community college, who received their undergraduate degree from a U.S. university, and who completed their BA by the year they turned 25 (8,270 women). Because these criteria provide a select subsample, we do not use survey weights in our analysis. Given the oversample of respondents in the sciences and engineering, our sample therefore includes relatively more PhDs and those born outside the U.S. Among these 8,270 women, we focus on the population of married mothers of children under age 6 , giving us a sample of 1,404 women. ${ }^{48}$

The NSCG captures very rich data on each individual's occupation, work environment, and education, including detailed field of study. By comparison, the NSCG captures more limited demographics. Most importantly, the survey captures very little information on spouses. We observe only whether the spouse works full-time, part-time, or is out of the labor force, and whether his job requires a BA.

Unfortunately the NSCG does not provide sufficient information to do an analysis of the effect of pre-birth work environment on post-birth labor supply. Because of its design, the NSCG captures some work information for 2000 as well as 2003. For instance, for those working in both periods, the survey captures information on the 2000 work environment by asking whether a given person has changed employers and/or jobs. For those not working, the survey provides most recent occupation and year of employment.

But this information is insufficient to capture 2000 work environment for the full population of women with first births between 2000 and 2003. For those in the labor force at both times, we observe pre-birth work environment for those who did not change jobs, but can

\footnotetext{
${ }^{48}$ Because the NSCG reports all children in the household, our sample also excludes women who report both children under age 6 and over age 18 (suggesting that one set may be step-children), and likewise exclude those women who are over age 50, for whom any children under age 6 are likely not their own. Among the remaining women with children under age 6, 94 percent are married.
} 
only approximate this for those who did. And for those out of the labor force, although we can distinguish occupation, this is insufficient for defining work environment. For instance, we can tell that a woman was a lawyer, but not if she worked for a large for-profit firm or for the government.

\section{A.1 Estimating Wages for Non-Working Mothers}

To calculate hourly wages for the working mothers, we use reported 2003 annualized salary and average hours worked per week, assuming 50 weeks worked per year (see the first panel of Table A-1). We translate these into year 2000 dollars using the Consumer Price Index for all urban consumers (US city averages for all items). We set as missing values wages for women who worked 10 or fewer hours per week, and hourly wages less than $\$ 6$ and greater than $\$ 300$. (These values are higher than the standard cutoffs in the literature, but reflect the education level of our population).

We use these values to estimate hourly wages for those who are not working (or for missing values). In particular, we begin by estimating a woman's predicted probability of working, $\hat{p}$, built from a specification that excludes wages. To allow for selection out of the labor force, we split the sample by the degree-specific medians of $\hat{p}$, and estimate wages separately within each half of the distribution. ${ }^{49}$ The controls in the wage equation include graduate degree, years' experience since degree completion, occupation, graduate and undergraduate institution type, undergraduate major, and region of residence.

The top panel of Table A-1 reports these predicted (log) wage values, both for the sample overall and separately for working mothers and those at home. Notice that for all but MDs, the mean estimated wages are higher for women out of the labor force. In some instances this speaks to composition. For instance, among PhDs this reflects an overrepresentation of professors among those working, and a corresponding over-representation of formerly biotech- and high-tech workers among those at home.

More broadly, however, among the working women we often find that the calculated hourly wage is higher among women who work shorter hours, in large part because it appears that salaries do not scale down as much as hours. Because these women tend to fall in the bottom half of the $\hat{p}$ distribution (as we would expect), their wages are especially important in predicting wages for the non-working women.

Table A-1 also shows that the fathers of MBAs have the least education; the fathers of

\footnotetext{
${ }^{49}$ This amounts to assuming selection on observables. As an alternative approach we estimate wages including the whole sample, thus assuming no selection. The results are qualitatively similar throughout the analysis.
} 
JDs have the most. This suggests that MBAs in the NSCG are a relatively less select group of women than those who select into other fields, especially law. Some of this difference may arise from our imprecise definition of graduate degree; it is easier to distinguish JDs and MDs based on their field of study and occupation, than it is to distinguish MBAs.

Table A-1: NSCG Summary Statistics

\begin{tabular}{|c|c|c|c|c|c|c|}
\hline & All & MD & PhD & $\mathbf{J D}$ & MBA & MA \\
\hline \multicolumn{7}{|l|}{ Salary and Wages $(2000 \$)$ : } \\
\hline \multicolumn{7}{|l|}{ If working: } \\
\hline Annualized salary ('000s) & $\begin{array}{c}55.7 \\
(41.5)\end{array}$ & $\begin{array}{c}96.2 \\
(55.4)\end{array}$ & $\begin{array}{c}55.8 \\
(36.0)\end{array}$ & $\begin{array}{c}74.3 \\
(41.5)\end{array}$ & $\begin{array}{c}67.1 \\
(41.3)\end{array}$ & $\begin{array}{c}44.9 \\
(34.4)\end{array}$ \\
\hline Weekly hours & $\begin{array}{c}37.1 \\
(14.8)\end{array}$ & $\begin{array}{c}43.6 \\
(18.6)\end{array}$ & $\begin{array}{c}38.5 \\
(16.5)\end{array}$ & $\begin{array}{c}37.4 \\
(13.7)\end{array}$ & $\begin{array}{c}38.3 \\
(11.9)\end{array}$ & $\begin{array}{c}35.5 \\
(14.0)\end{array}$ \\
\hline Hourly wage & $\begin{array}{l}30.85 \\
(21.25)\end{array}$ & $\begin{array}{l}51.68 \\
(34.58)\end{array}$ & $\begin{array}{c}30.13 \\
(16.87)\end{array}$ & $\begin{array}{c}38.46 \\
(17.26)\end{array}$ & $\begin{array}{c}35.45 \\
(19.30)\end{array}$ & $\begin{array}{c}25.95 \\
(17.60)\end{array}$ \\
\hline Predicted log hourly wage: & $\begin{array}{c}3.30 \\
(0.38)\end{array}$ & $\begin{array}{c}3.70 \\
(0.40)\end{array}$ & $\begin{array}{c}3.37 \\
(0.45)\end{array}$ & $\begin{array}{c}3.66 \\
(0.17)\end{array}$ & $\begin{array}{c}3.48 \\
(0.38)\end{array}$ & $\begin{array}{c}3.16 \\
(0.29)\end{array}$ \\
\hline If working & $\begin{array}{c}3.30 \\
(0.37)\end{array}$ & $\begin{array}{c}3.71 \\
(0.39)\end{array}$ & $\begin{array}{c}3.34 \\
(0.43)\end{array}$ & $\begin{array}{c}3.63 \\
(0.17)\end{array}$ & $\begin{array}{c}3.44 \\
(0.31)\end{array}$ & $\begin{array}{c}3.15 \\
(0.29)\end{array}$ \\
\hline If at home & $\begin{array}{c}3.30 \\
(0.41)\end{array}$ & $\begin{array}{c}3.64 \\
(0.58)\end{array}$ & $\begin{array}{c}3.49 \\
(0.53) \\
\end{array}$ & $\begin{array}{c}3.75 \\
(0.14) \\
\end{array}$ & $\begin{array}{c}3.58 \\
(0.54) \\
\end{array}$ & $\begin{array}{c}3.17 \\
(0.28)\end{array}$ \\
\hline \multicolumn{7}{|c|}{ Conventional Elements of the Labor Supply Decision $(X)$ : } \\
\hline Total children & $\begin{array}{c}1.90 \\
(0.86)\end{array}$ & $\begin{array}{c}1.99 \\
(0.94)\end{array}$ & $\begin{array}{c}1.85 \\
(0.79)\end{array}$ & $\begin{array}{c}1.94 \\
(0.89)\end{array}$ & $\begin{array}{c}1.90 \\
(0.83)\end{array}$ & $\begin{array}{c}1.89 \\
(0.86)\end{array}$ \\
\hline Works less than full-time (\%) & $\begin{array}{c}10.3 \\
(30.3) \\
\text { led }={ }^{\circ} \text { ot }\end{array}$ & $\begin{array}{l}21.7 \\
(41.4) \\
\%)\end{array}$ & $\begin{array}{c}12.7 \\
(33.4)\end{array}$ & $\begin{array}{c}7.9 \\
(27.1)\end{array}$ & $\begin{array}{c}9.9 \\
(30.0)\end{array}$ & $\begin{array}{c}8.7 \\
(28.1)\end{array}$ \\
\hline Science & $\begin{array}{c}33.3 \\
(47.1)\end{array}$ & $\begin{array}{c}22.6 \\
(42.0)\end{array}$ & $\begin{array}{c}51.3 \\
(50.1)\end{array}$ & $\begin{array}{c}20.2 \\
(40.3)\end{array}$ & $\begin{array}{c}34.0 \\
(47.6)\end{array}$ & $\begin{array}{c}32.2 \\
(46.8)\end{array}$ \\
\hline Social science & $\begin{array}{c}8.8 \\
(28.3)\end{array}$ & $\begin{array}{c}6.6 \\
(25.0)\end{array}$ & $\begin{array}{c}12.2 \\
(32.8)\end{array}$ & $\begin{array}{c}14.0 \\
(34.9)\end{array}$ & $\begin{array}{c}5.7 \\
(23.2)\end{array}$ & $\begin{array}{c}8.1 \\
(27.3)\end{array}$ \\
\hline Not required & $\begin{array}{c}25.2 \\
(43.4)\end{array}$ & $\begin{array}{c}31.1 \\
(46.5)\end{array}$ & $\begin{array}{c}14.8 \\
(35.6)\end{array}$ & $\begin{array}{c}18.4 \\
(38.9)\end{array}$ & $\begin{array}{c}29.8 \\
(45.9)\end{array}$ & $\begin{array}{c}26.9 \\
(44.4)\end{array}$ \\
\hline \multicolumn{7}{|l|}{ Proxies for household assets: $(\%)$} \\
\hline \multirow{2}{*}{$\begin{array}{l}\text { Private undergraduate } \\
\text { institution } \\
\text { Father } \leq \text { high school }\end{array}$} & $\begin{array}{c}43.3 \\
(49.6)\end{array}$ & $\begin{array}{c}49.5 \\
(50.2)\end{array}$ & $\begin{array}{c}50.5 \\
(50.1)\end{array}$ & $\begin{array}{c}51.8 \\
(50.2)\end{array}$ & $\begin{array}{c}40.4 \\
(49.2)\end{array}$ & $\begin{array}{c}40.2 \\
(49.1)\end{array}$ \\
\hline & $\begin{array}{c}24.9 \\
(43.3)\end{array}$ & $\begin{array}{c}23.6 \\
(42.7)\end{array}$ & $\begin{array}{c}18.5 \\
(38.9)\end{array}$ & $\begin{array}{c}14.9 \\
(35.8)\end{array}$ & $\begin{array}{c}31.2 \\
(46.5)\end{array}$ & $\begin{array}{c}26.8 \\
(44.3)\end{array}$ \\
\hline Live in same region as grew up (\%) & $\begin{array}{c}48.6 \\
(50.0)\end{array}$ & $\begin{array}{c}50.9 \\
(50.2)\end{array}$ & $\begin{array}{c}31.7 \\
(46.7)\end{array}$ & $\begin{array}{c}45.6 \\
(50.0)\end{array}$ & $\begin{array}{c}46.8 \\
(50.1)\end{array}$ & $\begin{array}{c}52.8 \\
(50.0)\end{array}$ \\
\hline \multicolumn{7}{|c|}{ Proxies for Taste-Based Elements, $\theta=(\zeta, \psi)$ : } \\
\hline Age & $\begin{array}{c}36.2 \\
(4.5)\end{array}$ & $\begin{array}{l}36.5 \\
(4.6)\end{array}$ & $\begin{array}{l}37.7 \\
(4.1)\end{array}$ & $\begin{array}{l}37.0 \\
(4.3)\end{array}$ & $\begin{array}{l}36.6 \\
(4.5)\end{array}$ & $\begin{array}{l}35.7 \\
(4.5)\end{array}$ \\
\hline \multirow[t]{2}{*}{ Minority $(\%)$} & $\begin{array}{c}23.3 \\
(42.3)\end{array}$ & $\begin{array}{c}34.9 \\
(47.9)\end{array}$ & $\begin{array}{c}28.6 \\
(45.3)\end{array}$ & $\begin{array}{c}26.3 \\
(44.2)\end{array}$ & $\begin{array}{c}24.8 \\
(43.4)\end{array}$ & $\begin{array}{c}20.0 \\
(40.0)\end{array}$ \\
\hline & & & & Con & nued on & ext page \\
\hline
\end{tabular}


Table A-1 - continued from previous page

\begin{tabular}{ccccccc}
\hline \hline & All & MD & PhD & JD & MBA & MA \\
\hline Undergraduate Major: (\%) & & & & & & \\
Biology & 20.1 & 74.3 & 25.9 & 0.9 & 4.3 & 17.2 \\
& $(40.1)$ & $(43.9)$ & $(43.9)$ & $(9.5)$ & $(20.4)$ & $(37.7)$ \\
Other sciences \& engineering & 16.8 & 7.6 & 22.8 & 6.3 & 23.0 & 17.0 \\
& $(37.4)$ & $(26.7)$ & $(42.0)$ & $(24.4)$ & $(42.2)$ & $(37.6)$ \\
Psychology & 12.7 & 9.5 & 20.6 & 8.1 & 4.3 & 13.3 \\
& $(33.3)$ & $(29.5)$ & $(40.6)$ & $(27.4)$ & $(20.4)$ & $(33.9)$ \\
Economics \& business & 11.3 & 0.0 & 3.7 & 14.4 & 47.5 & 8.0 \\
& $(31.7)$ & $(0.0)$ & $(18.9)$ & $(35.3)$ & $(50.1)$ & $(27.2)$ \\
Political science & 5.3 & 0.0 & 3.2 & 25.2 & 2.9 & 4.3 \\
& $(22.5)$ & $(0.0)$ & $(17.6)$ & $(43.6)$ & $(16.8)$ & $(20.2)$ \\
Other social studies & 22.5 & 4.8 & 13.2 & 15.3 & 9.4 & 29.9 \\
& $(41.8)$ & $(21.4)$ & $(34.0)$ & $(36.2)$ & $(29.2)$ & $(45.8)$ \\
English & 5.9 & 1.9 & 4.8 & 18.0 & 5.0 & 5.2 \\
& $(23.6)$ & $(13.7)$ & $(21.4)$ & $(38.6)$ & $(21.9)$ & $(22.2)$ \\
History & 2.3 & 1.0 & 3.2 & 10.8 & 1.4 & 1.3 \\
& $(15.0)$ & $(9.8)$ & $(17.6)$ & $(31.2)$ & $(12.0)$ & $(11.3)$ \\
\hline Sample Size: & $\mathbf{1 4 0 4}$ & $\mathbf{1 0 6}$ & $\mathbf{1 8 9}$ & $\mathbf{1 1 4}$ & $\mathbf{1 4 1}$ & $\mathbf{8 5 4}$ \\
(\% of total): & & $\mathbf{( 7 . 6 )}$ & $\mathbf{( 1 3 . 5 )}$ & $\mathbf{( 8 . 1 )}$ & $\mathbf{( 1 0 . 0 )}$ & $(\mathbf{6 0 . 8})$ \\
\hline \hline
\end{tabular}

NOTES:

Reported mean (and standard deviations) of a subset of the controls included in the specifications in Table 6. (See the notes to Table A-7 for the full set of controls.)

\section{A.2 Other Variable Definitions}

Lastly, for other variable definitions:

- For each respondent we observe highest degree attained, grouped by $\mathrm{PhD}, \mathrm{MA}$, or professional degree. We distinguish MBAs from MAs based on graduate field of study (business). Among those with professional degrees, we distinguish JDs, MDs, and those with specialized MAs, based on field of study and occupation. We group dentist, veterinarians, optometrists, and pharmacists with MDs.

- We define an undergraduate major as small if less than 1 percent of the (weighted) sample of NSCG respondents graduated in that major, using all respondents ages 34 to 40 .

- For MDs, JDs, and MBAs, we define a "matching" undergraduate major as biology, political science, and economics or business, respectively. For MAs and PhDs, we define the match based on reported field of major.

- We define respondents' as minority if they list themselves as at least partly minority. 


\section{B Harvard Graduates Data}

The Harvard college graduating classes of 1988 through 1991 included 6,764 students, of which 41 percent were female. This sample reflects those individuals listed in either their 10th or 15th anniversary reports, which includes anyone for whom the alumni association had a current or previous address. (For those who do not respond to the survey, the report lists only the name and address.) We focus on the 3,456 who responded to the 15th-year survey (51 percent of the sample overall, with a larger 55 percent of women). ${ }^{50}$ Appendix Section B.1 discusses the representativeness of the population who respond to the survey. Of these 3,456 graduates, 1,522 (44 percent) are women.

Our main sample is the 934 women who are married and have had their first child at the time of the 15 th anniversary survey ${ }^{51}$ For 743 of these women (80 percent), we can supplement these data with additional information from their 10th anniversary survey. From these, we separately focus on the 286 women that we observe both 10 and 15 years after college, who had their first child between these two points, who provide labor force and occupation data at each, and who do not hold a $\mathrm{PhD}$ or MD.

For the purpose of our analysis, we define a woman's labor supply based on her selfreported current occupation, supplemented by information provided in her narrative. ${ }^{52}$ For a small number of women, we infer that they are at home if they provide detailed information for their spouses' occupation, but none for their own. Or, if they listed two occupations, such as "Attorney, Mom", we assumed the second reflected her current situation and the first her occupation before leaving the labor force.

\section{B.1 Sample Selection into the 15th-Year Anniversary Report}

We next consider the representativeness, among female Harvard graduates, of the population who respond to the 15th-year anniversary survey. ${ }^{53}$ Table A-2 reports mean background

\footnotetext{
${ }^{50}$ This number includes 84 individuals captured because their spouse - a Harvard graduate in one of the four years covered - provided information for both. (We also use spouse data to supplement details missing from the self-reported information.) For those married to members of a different class, this means that the information reflects a period shortly before or after the 15 th year.

${ }^{51}$ This excludes 27 mothers who are unmarried at the time of the 15 th.

${ }^{52}$ Because we define 'at home' status based on current employment, women who report that they recently went back to work or that they anticipate leaving soon, are defined as 'at work'. Maternity leaves are coded as 'at work', but women who report that they are 'on leave' from their past position are coded as 'at home'.

${ }^{53}$ There is evidence that graduates who are married and/or have children are generally more likely to respond. For instance, taking the sample who report the year of their first birth in their 15th-year response, we can compare the 10th-year response rates of those who had their first birth in the 2 years prior to the 10thyear reunion, to those who have their first birth afterwards. In both genders we find higher response rates among the already-parents, although the difference is only statistically significant among men. Likewise, we see that among women (but not men), those who married recently before the 10th-year reunion are significantly more likely to respond, and among men (but not women), those who recently finished their
} 
characteristics available from the graduation yearbooks, comparing those women who are and are not observed in the 15th-year survey. Looking at the first set of columns, there is clear evidence that the women observed at the 15th year are a non-random sample of all Harvard graduates. In particular, if we use these background characteristics to predict who will respond to the survey, a $\chi^{2}$ test of their predictive power is highly statistically significant. Comparing across background characteristics, the most striking difference is by race: whites are more likely to respond.

Because our analysis focuses on the comparison of women who choose different graduate programs, an important question is whether selection into the sample varies systematically among women of different education types. Unfortunately a direct comparison is infeasible because we cannot observe the graduate education of those women who do not respond. However as an indirect test, we can compare the response rates among Harvard graduates in the undergraduate majors that are the primary feeders for three of the graduate degrees considered: biology (MDs), political science (JDs), and economics (MBAs). ${ }^{54}$ Because masters and doctoral degrees are granted across all fields, we have no similar means to compare reporting propensities for MAs and PhDs, or for those who get no additional schooling.

The foot of Table A-2 compares the 15th-year response rates for all female graduates to the response rates for women in these three majors. As we see, potential MBAs are the most likely to respond. Their response rate is significantly higher than all other majors combined, and than either potential MDs or JDs. (This might reflect the nature of the business world relative to other career paths, if MBAs are more likely to view the anniversary surveys as a networking mechanism.) This higher response rate, however, does not translate into a more representative sample. We instead find that as with potential JDs, among potential MBAs, background characteristics can predict who will respond (significant at the 5 percent level), whereas among potential MDs the response rate appears more random.

In combination, these results show two things. First it is clear that our responding sample is not randomly drawn from the full pool of Harvard graduates. In particular, in direct contrast to the NSCG sample, our Harvard sample under-represents minorities. Furthermore, because our results suggest that minority women tend to work at higher rates,

primary degree are more likely to respond.

${ }^{54}$ Among all respondents to the 15th year survey who have an MD, 38 percent hold a BA in biology. Similarly, among observed biology majors, 66 percent go on to get an MD. Among observed MBAs, 23 percent studied economics, and 44 percent of observed economics majors get an MBA; among JDs, 15 percent studied political science, and 44 percent of political science majors complete a JD. (Among all observed JDs, a larger 23 percent studied English. Among observed English majors, however, although 24 percent complete a JD, this is followed closely by 23 percent who get an MA, and 23 percent who complete no graduate degree. For that reason we do not treat an English undergraduate degree as a feeder for a law degree.) 


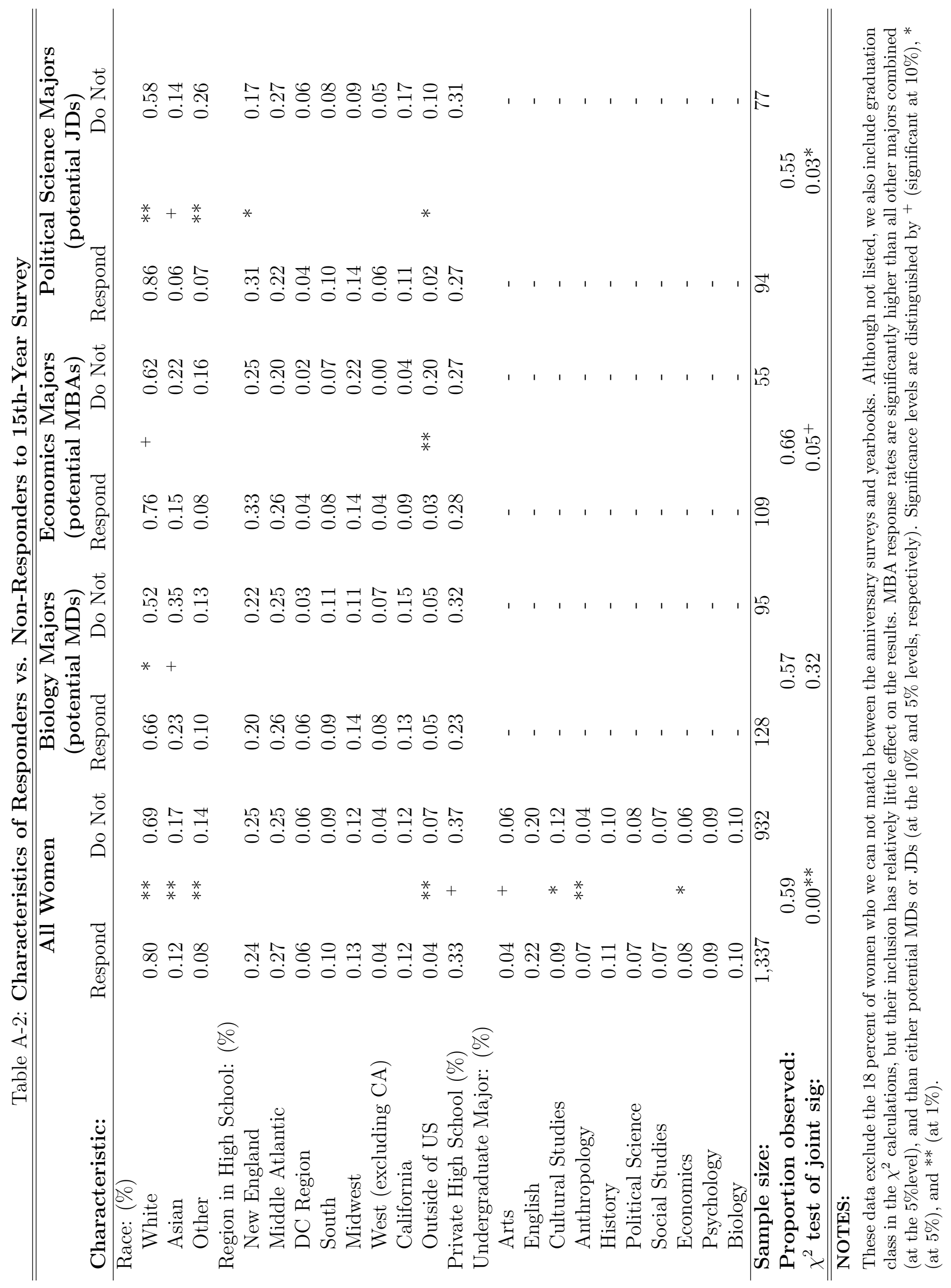


all else equal, our sample may therefore include a higher proportion of at-home mothers than among the full population of female Harvard graduates. (This may be tempered somewhat by the lower response rates among those who attended a private school, a characteristic that is instead associated with lower labor force participation among the observed sample.)

Our second result is that the level of selection likely varies across women who choose different career paths. For instance, based on the three degrees that we can match to specific undergraduate majors, we see that the observed sample of potential MDs is less strongly selected than the sample of either potential MBAs or potential JDs. Beyond the difference in reporting rates by race that is evident across all women, it is not obvious how these selection patterns will affect our overall results.

As a check, we therefore build a predicted probability of being included in our final sample - those women who respond to the 15th year anniversary survey and are married and have had a child by that point - based on characteristics observable at the time of graduation from college. We find that women included in our sample have a mean predicted probability of 0.40 of meeting these criteria, which is completely invariable across degrees (from 0.39 to 0.40$)$. Furthermore, if we include this predicted probability as a control in the Harvard labor supply probits in Table 6, it has no effect on the variation across degrees, and is itself completely uncorrelated with labor force status.

\section{B.2 Estimating Wages and Spouse's Salary}

Despite this rich professional data, we lack information on salaries and wages. We therefore had a career consultant build imputed salaries, for both mothers and their spouses, based on self-reported education, location, occupation, and firm. He used sources such as the Bureau of Labor Statistics' Occupational Employment Statistics, information from the Chronicle of Higher Education, and online sources such as CareerJournal.com, PayScale.com, Vault.com, and Indeed.com. For example, to determine the salary of an assistant US attorney, he used salaries reported on a Justice Department website for attorneys with similar years of experience. All salaries are updated to year 2000 dollars using the Consumer Price Index for all urban consumers (US city averages for all items).

Because these salary estimates are based on occupation-specific averages, one worry is that they will systematically understate the salaries received by this population of Harvard graduates. As a rough comparison, we can compare our values to those reported for women in the Harvard \& Beyond sample (Goldin and Katz, 2008). They report a mean 2005 full-time/full-year salary of $\$ 99,500$ (in year 2000 dollars), although because this reflects a combined value for cohorts graduating in approximately 1970, 1980, and 1990, it may be 
a poor estimate of the salaries received by the youngest cohort. ${ }^{55}$ By comparison, doing a back-of-the-envelope calculation, we estimate average annual salaries of $\$ 106,000 .{ }^{56}$ Thus from this (admittedly poor) comparison we see no evidence that our starting salaries are systematically too low for the female Harvard graduates.

Likewise, comparing our wage estimates for the working population of Harvard and NSCG mothers (see Tables A-1 and A-3, with Harvard wages calculated via the method described below), the Harvard wages are systematically higher. Thus although the building blocks for our salary estimates are based on occupation-specific averages, Harvard women are clearly distributed across a different, higher paid, set of jobs.

Even if our initial salary estimates are too low for this population of women, this is only problematic if the relative understatement varies across graduate degrees. Unfortunately Goldin \& Katz (2008) does not provide average salaries by degree. The only data available for a relevant comparison group (in terms of age, cohort, and education quality), that provides information by specific degree, is data for a recent cohort of graduates from the Booth School of Business at the University of Chicago (Bertrand et al., 2010).

Bertrand et al. report significantly higher earnings for MBA mothers than our estimates for these Harvard graduates. Measured 8 years post-MBA (approximately 15 years after college, given their average age at entry), they find mean and median annual salaries of $\$ 192,000$ and $\$ 138,000$, respectively (in year 2000 dollars). Given reported labor supply levels, these translate roughly into mean and median hourly wages of $\$ 79$ and $\$ 61$, both of which are higher than our estimated hourly wage of $\$ 50$. Yet if our wage values for these MBA women are especially understated compared to our estimated wages for the other degree groups, this will only dampen our result that MBA women are less likely to work.

This potential understatement of earnings may be more problematic in terms of spouse's salaries. Goldin \& Katz (2008) report average annual salaries of $\$ 165,300$ for men in the Harvard \& Beyond sample. (Again, because this value reflects data for all three cohorts, in this case this likely overstates the earnings of the youngest generation.) By comparison, looking only at the Harvard women who are married to Harvard men, our mean estimated spouses' salaries are much lower at $\$ 123,900$.

\footnotetext{
${ }^{55}$ It is unclear whether this suggests that this number over- or under-states the earnings received by the 1990 cohort. If there is a strong earnings gradient in experience, mean 1990 cohort salaries may be lower; but if recent cohorts have greater representation among high-paying positions, 1990 salaries may be higher.

${ }^{56}$ As discussed below, our initial salary estimates reflect "gender-neutral" values. This average uses a back-of-the-envelope calculation of "gendered" salaries by applying our motherhood wage gap values to our initial gender-neutral salaries (thus ignoring the differences in labor supply by parental status). See below for greater detail on how we calculate these wage gap ratios.
} 
Furthermore, given the high rate of intermarriage by graduate degree, this may be especially important if we are systematically understating the earnings of MBA men. Goldin \& Katz find especially high salaries for the MBA men ${ }^{57}$, and likewise, Bertrand et al. (2010) find mean and median earnings of $\$ 337,000$ and $\$ 177,000$, respectively. By comparison, we estimate average salaries of $\$ 120,800$ for Harvard-graduate spouses holding MBAs.

Thus, potential underestimation of earnings for husbands holding MBAs may help explain the especially low labor force participation rates observed among our sample of Harvard MBA women. Yet given the size of the level differences, and the fact that they remain after controlling for spouse's graduate degree, it seems highly unlikely that it would explain the full effect. Furthermore, in a sensitivity analysis in which we instrument for spouse's salary using distribution dummies, and force into the top $5 \%$ those spouse's with job titles suggesting especially high earnings, the degree coefficients are unchanged. ${ }^{58}$

Taking these salary estimates as our starting point, note that since we did not provide gender or parental status to our career consultant, our values reflect "gender neutral" salaries. (We did not want him to incorporate his own statistical discrimination into these numbers.) To translate these salaries into "gendered" wages for our population of Harvard women, we use the following approach. (Because most of the Harvard spouses work in generally male fields, we do not adjust their salaries.)

- To provide a population at roughly the same stage of their careers as our Harvard sample, we use an NSCG sample of men and women ages 30 to 45 (and otherwise selected as in Appendix A). We then create detailed graduate degree and occupation groupings to capture the types of jobs observed among our Harvard women.

- We calculate average weekly hours using the full sample of men and women in a given degree/occupation group. Assuming 50 weeks worked per year, we apply these numbers to our gender-neutral Harvard salaries to create "gender-neutral" wages.

- Because much of the gender wage gap arises only after children (Bertrand et al., 2010), within each degree/occupation group we calculate separate measures of the gender wage gap for women with and without children. In particular, we use the NSCG data to calculate two ratios: the average experience-adjusted wages of women with children compared to the average wage overall, and likewise the average experienceadjusted wages of women without children compared to all. We apply these ratios to our "gender neutral" values to calculate "gendered" wages.

\footnotetext{
${ }^{57}$ Personal communication with Lawrence Katz, December, 2008.

${ }^{58}$ Before this adjustment, more than half of the men in this group are MDs (with mean estimated earnings of over $\$ 300,000)$; in this adjustment we re-categorize 21 men, of which 19 hold MBAs.
} 
- For doctors, because the NSCG lacks area of specialty (e.g., pediatrics), to calculate "gender-neutral" hourly wages we rely on average weekly hours data per specialty as reported in the American Medical Association's Physician Socioeconomic Statistics, 2000-2002. Because this source does not provide salary data by gender and parental status, we must rely on the NSCG data to transform these into "gendered" wages. There exist large differences in gender distribution across medical specialties, however, and likewise large differences in salary by specialty. ${ }^{59}$ We therefore build the wage ratio for mothers by comparing their average wages to average wages for all female doctors. This effectively assumes that the distribution across specialties is the same for female doctors, regardless of parental status, and that the scaling ratio is 1.0 for non-moms.

- For MBAs, the NSCG captures too few women who work in high-level management positions to distinguish across sectors (we group finance and consulting, high tech and other science-related industries, and all other fields). Because high-level MBAs work longer hours, we use average hours for this combined set to calculate gender-neutral wages. To scale these into "gendered" wages, we then use wage ratios calculated separately for the three sectors, after combining the high- and non-high level MBAs. ${ }^{60}$

The first panel of Table A-3 lists our initial gender-neutral salary estimates for the working Harvard women, and our subsequent "gendered" wage values.

To estimate wages for the non-working women and those with missing values, we follow the same approach as in Section A.1.61 In this case, the wage equation controls include graduate degree, years experience since completing that degree, 10th-year wage interacted by degree, and region. The top panel of Table A-3 reports mean predicted log hourly wages, both for the sample as a whole, and separately for those women working and those at home.

\footnotetext{
${ }^{59}$ For instance, among our Harvard sample, 27 percent are pediatricians (with an average gender-neutral estimated salary of $\$ 136,000$ ) and 5 percent are surgeons (estimated salary of $\$ 219,000$ ). By comparison, among the full population of doctors reported in the Physician Socioeconomic Statistics, 2000-2002, 11 percent are pediatricians and 19 percent are surgeons.

${ }^{60}$ This provides scaling ratios of 87 to 91 percent. These line up well with an estimated scaling ratio of 88 percent calculated using median hours and salary data for the MBA graduates of Chicago's Booth School of Business (Bertrand et al., 2010).

${ }^{61}$ For 10 percent of those working, we lack 15th-year salaries because we lacked sufficient occupation data.
} 
Table A-3: Harvard Sample Summary Statistics

\begin{tabular}{|c|c|c|c|c|c|c|c|}
\hline & All & MD & PhD & JD & MBA & MA & None \\
\hline \multicolumn{8}{|c|}{ Salary and Wage Estimates at 15th $(2000 \$)$ : } \\
\hline \multicolumn{8}{|c|}{ If working: } \\
\hline Gender-neutral salary ('000s) & $\begin{array}{l}115.2 \\
(74.9)\end{array}$ & $\begin{array}{l}166.5 \\
(59.5)\end{array}$ & $\begin{array}{c}70.0 \\
(27.5)\end{array}$ & $\begin{array}{l}136.1 \\
(69.5)\end{array}$ & $\begin{array}{c}138.6 \\
(107.4)\end{array}$ & $\begin{array}{c}66.1 \\
(39.8)\end{array}$ & $\begin{array}{c}80.7 \\
(51.8)\end{array}$ \\
\hline 'Gendered' hourly wage & $\begin{array}{c}43.32 \\
(24.57)\end{array}$ & $\begin{array}{c}58.11 \\
(20.92)\end{array}$ & $\begin{array}{c}29.24 \\
(10.83)\end{array}$ & $\begin{array}{c}48.10 \\
(21.15)\end{array}$ & $\begin{array}{c}49.63 \\
(37.18)\end{array}$ & $\begin{array}{c}30.91 \\
(16.32)\end{array}$ & $\begin{array}{c}34.95 \\
(19.91)\end{array}$ \\
\hline Predicted log wage: & $\begin{array}{c}3.61 \\
(0.32)\end{array}$ & $\begin{array}{c}4.00 \\
(0.16)\end{array}$ & $\begin{array}{c}3.33 \\
(0.16)\end{array}$ & $\begin{array}{c}3.77 \\
(0.21)\end{array}$ & $\begin{array}{c}3.76 \\
(0.27)\end{array}$ & $\begin{array}{c}3.29 \\
(0.19)\end{array}$ & $\begin{array}{c}3.44 \\
(0.12)\end{array}$ \\
\hline If working & $\begin{array}{c}3.63 \\
(0.33)\end{array}$ & $\begin{array}{c}4.00 \\
(0.17)\end{array}$ & $\begin{array}{c}3.33 \\
(0.16)\end{array}$ & $\begin{array}{c}3.78 \\
(0.22)\end{array}$ & $\begin{array}{c}3.78 \\
(0.29)\end{array}$ & $\begin{array}{c}3.30 \\
(0.19)\end{array}$ & $\begin{array}{c}3.45 \\
(0.12)\end{array}$ \\
\hline If at home & $\begin{array}{c}3.53 \\
(0.28)\end{array}$ & $\begin{array}{c}4.03 \\
(0.11)\end{array}$ & $\begin{array}{c}3.36 \\
(0.18)\end{array}$ & $\begin{array}{c}3.74 \\
(0.17)\end{array}$ & $\begin{array}{c}3.71 \\
(0.21)\end{array}$ & $\begin{array}{c}3.25 \\
(0.18)\end{array}$ & $\begin{array}{c}3.41 \\
(0.13)\end{array}$ \\
\hline \multicolumn{8}{|l|}{ Additional proxies for own wage: } \\
\hline Top 10 graduate program (\%) & $\begin{array}{c}47.5 \\
(50.0)\end{array}$ & $\begin{array}{c}34.4 \\
(47.7)\end{array}$ & $\begin{array}{c}53.0 \\
(50.1)\end{array}$ & $\begin{array}{c}44.4 \\
(49.8)\end{array}$ & $\begin{array}{c}70.3 \\
(45.9)\end{array}$ & $\begin{array}{c}40.4 \\
(49.2)\end{array}$ & $\begin{array}{l}- \\
-\end{array}$ \\
\hline Extra Degree (non-MA) (\%) & $\begin{array}{c}2.2 \\
(14.7) \\
\end{array}$ & $\begin{array}{c}3.9 \\
(19.4) \\
\end{array}$ & $\begin{array}{c}0.9 \\
(9.2) \\
\end{array}$ & $\begin{array}{c}2.6 \\
(15.8) \\
\end{array}$ & $\begin{array}{c}2.2 \\
(14.6) \\
\end{array}$ & $\begin{array}{c}1.2 \\
(10.9) \\
\end{array}$ & $\begin{array}{l}- \\
- \\
\end{array}$ \\
\hline \multicolumn{8}{|c|}{ Conventional Elements of the Labor Supply Decision $(X)$ : } \\
\hline Total children & $\begin{array}{c}1.88 \\
(0.79)\end{array}$ & $\begin{array}{c}1.84 \\
(0.67)\end{array}$ & $\begin{array}{c}1.74 \\
(0.78)\end{array}$ & $\begin{array}{l}1.94 \\
(0.74)\end{array}$ & $\begin{array}{l}1.88 \\
(0.85)\end{array}$ & $\begin{array}{l}1.86 \\
(0.88)\end{array}$ & $\begin{array}{c}1.97 \\
(0.79)\end{array}$ \\
\hline \multicolumn{8}{|l|}{ Proxies for spouse's earnings: } \\
\hline Salary $(’ 000,2000 \$)$ & $\begin{array}{l}119.3 \\
(77.4)\end{array}$ & $\begin{array}{l}141.8 \\
(83.0)\end{array}$ & $\begin{array}{c}93.8 \\
(58.9)\end{array}$ & $\begin{array}{l}129.4 \\
(87.6)\end{array}$ & $\begin{array}{l}133.6 \\
(76.7)\end{array}$ & $\begin{array}{l}107.7 \\
(75.1)\end{array}$ & $\begin{array}{l}101.0 \\
(58.4)\end{array}$ \\
\hline $\begin{array}{l}\text { Top } 10 \text { graduate }(\%) \\
\text { institution }\end{array}$ & $\begin{array}{l}48.3 \\
(50.0)\end{array}$ & $\begin{array}{c}36.2 \\
(48.3)\end{array}$ & $\begin{array}{c}48.5 \\
(50.2)\end{array}$ & $\begin{array}{c}45.1 \\
(49.9)\end{array}$ & $\begin{array}{c}64.2 \\
(48.2)\end{array}$ & $\begin{array}{c}43.0 \\
(49.8)\end{array}$ & $\begin{array}{c}56.0 \\
(50.0)\end{array}$ \\
\hline \multicolumn{8}{|l|}{ Spouse's graduate degree: $(\%)$} \\
\hline $\mathrm{MD}$ & $\begin{array}{l}11.9 \\
(32.4)\end{array}$ & $\begin{array}{c}43.5 \\
(49.7)\end{array}$ & $\begin{array}{c}6.0 \\
(23.8)\end{array}$ & $\begin{array}{c}3.6 \\
(18.6)\end{array}$ & $\begin{array}{c}8.0 \\
(27.2)\end{array}$ & $\begin{array}{c}7.2 \\
(26.0)\end{array}$ & $\begin{array}{c}4.3 \\
(20.3)\end{array}$ \\
\hline $\mathrm{PhD}$ & $\begin{array}{l}12.6 \\
(33.2)\end{array}$ & $\begin{array}{l}13.6 \\
(34.4)\end{array}$ & $\begin{array}{c}41.0 \\
(49.4)\end{array}$ & $\begin{array}{c}7.7 \\
(26.7)\end{array}$ & $\begin{array}{c}5.1 \\
(22.0)\end{array}$ & $\begin{array}{l}10.8 \\
(31.2)\end{array}$ & $\begin{array}{c}5.5 \\
(22.9)\end{array}$ \\
\hline $\mathrm{JD}$ & $\begin{array}{c}18.2 \\
(38.6)\end{array}$ & $\begin{array}{c}9.1 \\
(28.8)\end{array}$ & $\begin{array}{c}15.4 \\
(36.2)\end{array}$ & $\begin{array}{c}49.0 \\
(50.1)\end{array}$ & $\begin{array}{c}6.5 \\
(24.8)\end{array}$ & $\begin{array}{c}7.2 \\
(26.0)\end{array}$ & $\begin{array}{c}12.9 \\
(33.6)\end{array}$ \\
\hline MBA & $\begin{array}{l}16.8 \\
(37.4)\end{array}$ & $\begin{array}{c}9.7 \\
(29.7)\end{array}$ & $\begin{array}{c}4.3 \\
(20.3)\end{array}$ & $\begin{array}{c}11.2 \\
(31.6)\end{array}$ & $\begin{array}{c}46.4 \\
(50.1)\end{array}$ & $\begin{array}{c}16.3 \\
(37.0)\end{array}$ & $\begin{array}{c}14.7 \\
(35.5)\end{array}$ \\
\hline MA & $\begin{array}{l}10.7 \\
(30.9)\end{array}$ & $\begin{array}{c}2.6 \\
(16.0)\end{array}$ & $\begin{array}{c}17.1 \\
(37.8)\end{array}$ & $\begin{array}{c}4.6 \\
(21.0)\end{array}$ & $\begin{array}{l}11.6 \\
(32.1)\end{array}$ & $\begin{array}{c}21.1 \\
(40.9)\end{array}$ & $\begin{array}{c}9.8 \\
(29.8)\end{array}$ \\
\hline No degree & $\begin{array}{c}29.8 \\
(45.7)\end{array}$ & $\begin{array}{c}21.4 \\
(41.2)\end{array}$ & $\begin{array}{c}16.2 \\
(37.0)\end{array}$ & $\begin{array}{c}24.0 \\
(42.8)\end{array}$ & $\begin{array}{c}22.5 \\
(41.9)\end{array}$ & $\begin{array}{c}37.3 \\
(48.5)\end{array}$ & $\begin{array}{c}52.8 \\
(50.1)\end{array}$ \\
\hline Private high school (\%) & $\begin{array}{c}35.7 \\
(47.9)\end{array}$ & $\begin{array}{c}32.7 \\
(47.1)\end{array}$ & $\begin{array}{c}32.6 \\
(47.1)\end{array}$ & $\begin{array}{c}35.8 \\
(48.1)\end{array}$ & $\begin{array}{c}40.6 \\
(49.3)\end{array}$ & $\begin{array}{c}36.7 \\
(48.4)\end{array}$ & $\begin{array}{c}35.3 \\
(48.0)\end{array}$ \\
\hline $\begin{array}{l}\text { Live in same region } \\
\text { as grew up (\%) }\end{array}$ & $\begin{array}{c}36.1 \\
(48.0)\end{array}$ & $\begin{array}{c}40.1 \\
(49.2)\end{array}$ & $\begin{array}{c}30.5 \\
(46.3)\end{array}$ & $\begin{array}{c}36.4 \\
(48.2)\end{array}$ & $\begin{array}{c}32.8 \\
(47.1)\end{array}$ & $\begin{array}{c}36.7 \\
(48.4)\end{array}$ & $\begin{array}{c}37.5 \\
(48.6)\end{array}$ \\
\hline
\end{tabular}


Table A-3 - continued from previous page

\begin{tabular}{|c|c|c|c|c|c|c|c|}
\hline & All & MD & PhD & JD & MBA & MA & None \\
\hline \multicolumn{8}{|c|}{ Proxies for Taste-Based Elements, $\theta=(\zeta, \psi)$ : } \\
\hline Changed name at marriage (\%) & $\begin{array}{c}57.1 \\
(49.5)\end{array}$ & $\begin{array}{c}50.6 \\
(50.2)\end{array}$ & $\begin{array}{c}39.3 \\
(49.1)\end{array}$ & $\begin{array}{c}56.6 \\
(49.7)\end{array}$ & $\begin{array}{c}73.9 \\
(44.1)\end{array}$ & $\begin{array}{c}52.4 \\
(50.1)\end{array}$ & $\begin{array}{c}66.9 \\
(47.2)\end{array}$ \\
\hline \multicolumn{8}{|l|}{ Age gap with spouse: } \\
\hline Older $(\%)$ & $\begin{array}{c}7.4 \\
(26.2)\end{array}$ & $\begin{array}{c}9.7 \\
(29.7)\end{array}$ & $\begin{array}{c}6.0 \\
(23.8)\end{array}$ & $\begin{array}{c}7.1 \\
(25.8)\end{array}$ & $\begin{array}{c}5.8 \\
(23.5)\end{array}$ & $\begin{array}{c}7.2 \\
(26.0)\end{array}$ & $\begin{array}{c}8.0 \\
(27.2)\end{array}$ \\
\hline Years, if not older & $\begin{array}{c}1.2 \\
(2.6)\end{array}$ & $\begin{array}{c}0.8 \\
(2.0)\end{array}$ & $\begin{array}{c}1.1 \\
(2.3)\end{array}$ & $\begin{array}{c}1.3 \\
(3.3)\end{array}$ & $\begin{array}{c}1.4 \\
(2.7)\end{array}$ & $\begin{array}{c}1.4 \\
(2.6)\end{array}$ & $\begin{array}{c}1.0 \\
(2.3)\end{array}$ \\
\hline First child before school (\%) & $\begin{array}{c}3.4 \\
(18.1)\end{array}$ & $\begin{array}{c}0.6 \\
(8.1)\end{array}$ & $\begin{array}{c}0.9 \\
(9.2)\end{array}$ & $\begin{array}{c}5.1 \\
(22.1)\end{array}$ & $\begin{array}{c}2.9 \\
(16.8)\end{array}$ & $\begin{array}{c}6.0 \\
(23.9)\end{array}$ & - \\
\hline Played sports in college $(\%)$ & $\begin{array}{c}31.2 \\
(46.4)\end{array}$ & $\begin{array}{c}29.9 \\
(46.0)\end{array}$ & $\begin{array}{c}17.9 \\
(38.5)\end{array}$ & $\begin{array}{c}26.7 \\
(44.4)\end{array}$ & $\begin{array}{c}39.1 \\
(49.0)\end{array}$ & $\begin{array}{c}38.1 \\
(48.7)\end{array}$ & $\begin{array}{c}33.1 \\
(47.2)\end{array}$ \\
\hline Minority (\%) & $\begin{array}{c}16.6 \\
(37.3)\end{array}$ & $\begin{array}{c}24.5 \\
(43.1)\end{array}$ & $\begin{array}{c}11.6 \\
(32.2)\end{array}$ & $\begin{array}{c}17.0 \\
(37.7)\end{array}$ & $\begin{array}{c}21.1 \\
(41.0)\end{array}$ & $\begin{array}{c}11.6 \\
(32.1)\end{array}$ & $\begin{array}{c}12.5 \\
(33.2)\end{array}$ \\
\hline \multicolumn{8}{|l|}{ Undergraduate Major: (\%) } \\
\hline Biology & $\begin{array}{c}9.9 \\
(29.9)\end{array}$ & $\begin{array}{c}39.5 \\
(49.0)\end{array}$ & $\begin{array}{c}11.6 \\
(32.2)\end{array}$ & $\begin{array}{c}1.1 \\
(10.6)\end{array}$ & $\begin{array}{c}3.1 \\
(17.5)\end{array}$ & $\begin{array}{c}2.7 \\
(16.3)\end{array}$ & $\begin{array}{c}2.2 \\
(14.7)\end{array}$ \\
\hline Other sciences \& engineering & $\begin{array}{c}5.1 \\
(21.9)\end{array}$ & $\begin{array}{c}4.1 \\
(19.9)\end{array}$ & $\begin{array}{c}20.0 \\
(40.2)\end{array}$ & $\begin{array}{c}2.3 \\
(14.9)\end{array}$ & $\begin{array}{c}0.8 \\
(8.8)\end{array}$ & $\begin{array}{c}4.1 \\
(19.9)\end{array}$ & $\begin{array}{c}4.4 \\
(20.6)\end{array}$ \\
\hline Psychology & $\begin{array}{c}10.4 \\
(30.5)\end{array}$ & $\begin{array}{c}10.2 \\
(30.4)\end{array}$ & $\begin{array}{c}10.5 \\
(30.9)\end{array}$ & $\begin{array}{c}8.0 \\
(27.1)\end{array}$ & $\begin{array}{c}10.2 \\
(30.3)\end{array}$ & $\begin{array}{c}13.6 \\
(34.4)\end{array}$ & $\begin{array}{c}10.3 \\
(30.5)\end{array}$ \\
\hline Economics/business & $\begin{array}{c}8.8 \\
(28.4)\end{array}$ & $\begin{array}{c}2.7 \\
(16.3)\end{array}$ & $\begin{array}{c}2.1 \\
(14.4)\end{array}$ & $\begin{array}{c}6.3 \\
(24.3)\end{array}$ & $\begin{array}{c}27.3 \\
(44.7)\end{array}$ & $\begin{array}{c}4.1 \\
(19.9)\end{array}$ & $\begin{array}{c}11.0 \\
(31.4)\end{array}$ \\
\hline Political science & $\begin{array}{c}6.9 \\
(25.3)\end{array}$ & $\begin{array}{c}2.0 \\
(14.2)\end{array}$ & $\begin{array}{c}2.1 \\
(14.4)\end{array}$ & $\begin{array}{c}17.0 \\
(37.7)\end{array}$ & $\begin{array}{c}8.6 \\
(28.1)\end{array}$ & $\begin{array}{c}3.4 \\
(18.2)\end{array}$ & $\begin{array}{c}4.4 \\
(20.6)\end{array}$ \\
\hline Other social studies & $\begin{array}{c}6.3 \\
(24.3)\end{array}$ & $\begin{array}{c}1.4 \\
(11.6)\end{array}$ & $\begin{array}{c}3.2 \\
(17.6)\end{array}$ & $\begin{array}{c}8.5 \\
(28.0)\end{array}$ & $\begin{array}{c}10.9 \\
(31.3)\end{array}$ & $\begin{array}{c}6.1 \\
(24.1)\end{array}$ & $\begin{array}{c}6.6 \\
(25.0)\end{array}$ \\
\hline English & $\begin{array}{c}21.0 \\
(40.7)\end{array}$ & $\begin{array}{c}12.2 \\
(32.9)\end{array}$ & $\begin{array}{c}22.1 \\
(41.7)\end{array}$ & $\begin{array}{c}26.7 \\
(44.4)\end{array}$ & $\begin{array}{c}14.1 \\
(34.9)\end{array}$ & $\begin{array}{c}23.1 \\
(42.3)\end{array}$ & $\begin{array}{c}26.5 \\
(44.3)\end{array}$ \\
\hline History & $\begin{array}{c}10.9 \\
(31.1)\end{array}$ & $\begin{array}{c}10.9 \\
(31.3)\end{array}$ & $\begin{array}{c}8.4 \\
(27.9)\end{array}$ & $\begin{array}{c}14.2 \\
(35.0)\end{array}$ & $\begin{array}{c}10.9 \\
(31.3)\end{array}$ & $\begin{array}{c}6.8 \\
(25.3)\end{array}$ & $\begin{array}{c}12.5 \\
(33.2)\end{array}$ \\
\hline $\begin{array}{l}\text { Sample Size: } \\
\text { (\% of total): }\end{array}$ & 934 & $\begin{array}{c}154 \\
(16.5)\end{array}$ & $\begin{array}{c}117 \\
(12.5)\end{array}$ & $\begin{array}{c}196 \\
(21.0)\end{array}$ & $\begin{array}{c}138 \\
(14.8)\end{array}$ & $\begin{array}{c}166 \\
(17.8)\end{array}$ & $\begin{array}{c}163 \\
(17.5)\end{array}$ \\
\hline
\end{tabular}

Reported mean (and standard deviations) of a subset of the controls included in the specifications in Table 6. (See the notes to Table A-7 for the full set of controls.)

\section{B.3 Other Variable Definitions}

See Appendix Section A.2 as a starting point for how we define specific controls. For those variables distinct to the Harvard sample (or that are created in a slightly different way), we define each by the following means:

- For women with more than one graduate degree, we categorize the professional degrees (JD, MBA, or MD) as the primary degree, or define the primary degree based on its alignment with their occupation. For instance, women with an $\mathrm{MD} / \mathrm{PhD}$ who are practicing doctors are categorized as an MD. We define an LLM, masters of law, as 
a JD for those practicing law with no additional law degree. When controlling for extra degrees, we exclude those MAs that appear to be an intermediate step towards a completed PhD.

- We define gender, as well as race and ethnicity, as best estimated from yearbook photos and graduates' names.

- For MDs, JDs, and MBAs, we define top-10 graduate programs using the U.S. News and World Report professional school rankings for 2001. Because we often lack specific field for many PhDs and MAs, we define top-10 status based on the U.S. News and World Report 2001 rankings for top research universities. Likewise, for the spouses, we define the top 20 undergraduate programs using the 2001 rankings of the top 15 research universities and the top 5 liberal arts schools (excluding all-women's colleges).

- We define an undergraduate major as small if fewer than 50 individuals graduated in that major, using the full sample of graduates from the classes of 1988 through 1991 that we can observe in the graduation yearbooks.

- We define own and spouse's age based on year of graduation from college, assuming all were 22 at the time. We define spouses to be of the same age if, by this measure, they are the same age, or $+/-1$ year.

- We use Peterson's Private Secondary Schools and the yearbook information on the high school attended to distinguish which graduates attended a private school.

- We classify the top 25 cities, using 1990 population, as our measure of 'big' cities.

- We define a person as having grown up in a 'low-density' state if their state of residence in high school had a year 2000 density of fewer than 100 people per square mile.

- To estimate whether the first child is born before graduate school, we estimate average schooling lengths as follows: for PhDs we assume 8 years for the humanities, 7 years for the sciences, 10 years for education, and 6 years for economics (Russo, 2004; Berger, 2007). We assign a length of 8 years for those with an unknown field, but, as with all degrees, we bound the length to have begun at the year of college graduation. For professional non-business masters we assume 2 years, except for architecture degrees (3 years) and British degrees (1 year). For those with an MA or MS in an undefined field, where some of these degrees will reflect 2-year programs and others longer, unfinished PhDs, we assume an average length of 2.5 years. Most of the women estimated to have had their first child before entering graduate school attended programs with concrete lengths (JDs and specific MA programs). 
Lastly, Table A-4 lists the firms included in Working Mother Magazine's 2001 list of "Best Places" to work, and the Yale Law Women's 2004 list of "Top-10 Family Friendly Firms".

\section{Selection into Parenthood}

One worry in considering the effect of work environment on mothers' labor force participation is that work environment may influence the decision to have children. If some women in nonfamily-friendly jobs respond by foregoing children, the average taste for kids among those who become mothers will be higher among mothers from a non-family-friendly environment. If this is then positively correlated with taste for time at home, mean labor force participation rates among those women will be driven downwards because of this stronger taste for time at home.

A first, indirect, test of whether work environment influences the decision to have children, is to compare across graduate degrees the proportion of women who are mothers. If, for instance, MBAs are more likely to work in a non-family-friendly environment, this may translate into a smaller proportion having children.

Using the NSCG sample reflected in Table 1, we test whether the proportion of mothers varies by graduate degree. Compared to all women with a graduate degree, only women with a $\mathrm{PhD}$ are significantly less likely to have children. MBAs are in fact more likely to be mothers than any other degree group other than MDs.

Likewise, using the Harvard sample reflected in Table 1 we find the exact same pattern. Across graduate degrees, MDs are most likely to have children, followed closely by MBAs (both rates significantly higher than the average overall), and $\mathrm{PhDs}$ are significantly less likely to be mothers. Thus, by this admittedly weak test, we find no evidence that work environment influences the decision to have children.

For the Harvard longitudinal sample we can test this more directly. Expanding this sample to include women with no children (but who otherwise fit the criteria discussed in Section 4.2), we find that women who were in non-family-friendly work environments 10 years after graduation are equally likely to have children as those who were in family-friendly jobs. The proportion is likewise almost exactly equal just among the women with MBAs. Thus we again find no evidence that work environment influences the propensity to have children.

A second consideration is whether there is evidence of selection into parenthood on ability. If mothers are systematically positively selected, this will increase their marginal benefit of working and thus raise their labor force participation. If the level of selection 


\section{Table A-4: Family-Friendly Firms}

\begin{tabular}{|c|c|c|}
\hline Abbott Laboratories & First Tennessee Bank & Patagonia \\
\hline ABN AMRO North America & Fleet Boston Financial & Paul Hastings* \\
\hline AFLAC & Ford Motor & Pearson Education \\
\hline Allstate Insurance & Genentech & Pfizer \\
\hline American Airlines & General Mills & Phoenix Companies \\
\hline American Express & General Motors & The PNC Financial Srvs Grp \\
\hline American Home Products & Gibson, Dunn \& Crutcher* & PricewaterhouseCoopers \\
\hline Arnold \& Porter** & GlaxoSmithKline & Principal Financial Group \\
\hline Arthur Andersen & Goldman Sachs & Procter \& Gamble \\
\hline Bank of America & Hewlett-Packard & Prudential Financial \\
\hline Bank One & Hoffman-La Roche & Republic Bancorp \\
\hline Baptist Health South Florida & Household International & Ropes \& Gray* \\
\hline Bausch \& Lomb & IBM & SAS Institute \\
\hline Bon Secours Richmond Health & Inova Health System & S.C. Johnson \& Son \\
\hline Booz Allen Hamilton & Johnson \& Johnson & Schering-Plough \\
\hline BP America Upstream & JPMorgan Chase & Sears, Roebuck and Co. \\
\hline Bristol-Myers Squibb & KPMG & Security Benefit Group \\
\hline BryanLGH Medical Center & Kraft Foods & Simpson Thacher* \\
\hline Carlson Companies & Lincoln Financial Group & The St. Paul Companies \\
\hline Cigna & Liz Claiborne & State Street Corporation \\
\hline Cinergy & Lucent Technologies & Sun Microsystems \\
\hline Cisco & Marriott International & Synovus Financial \\
\hline Citigroup & MBNA America Bank & Target \\
\hline Cleary Gottlieb* & McDonalds Corporation & Texas Instruments \\
\hline Computer Associates & Merck \& Co. & TIAA-CREF \\
\hline Corning & Merrill Lynch & Toms of Maine \\
\hline Covington \& Burling* & MetLife & TRW \\
\hline Cravath, Swaine \& Moore* & Morgan Stanley & Union Pacific Railroad \\
\hline DaimlerChrysler & Morrison \& Foerster & United Airlines \\
\hline Debevoise \& Plimpton* & Mutual of Omaha & USAA Life Insurance Co. \\
\hline Deloitte \& Touche & New York Life Insurance & The Vanguard Group \\
\hline Discovery Communications & The New York Times & Verizon/Verizon Wireless \\
\hline Eastman Kodak & Northern Trust & Vivendi Universal \\
\hline Edward Jones & Northwestern Memorial & Wachovia \\
\hline Eli Lilly & HealthCare & West Group \\
\hline Ernst \& Young & Novant Health & Wilmer Hale* \\
\hline Fannie Mae & Novartis Pharmaceuticals & Zurich North America \\
\hline
\end{tabular}

NOTES:

Law firms marked with * reflect those included on the 2004 list of 'Top 10 Family-Friendly Firm', as designated by the Yale Law Women. The remaining firms are those included on the 2001 Working Mother Magazine's list of 'top 100' places to work. Firms listed with ** appear on both lists. Working Mother ranks corporations both by the number and types of work-family benefits offered, and by the proportion of employees who use them. We use the October 2001 rankings as roughly representative of the period 10 to 15 years after graduation for our cohorts. The Yale Law Women's listing can be found at http://media.gibsondunn.com/fstore/pubs/YaleTop10.pdf, and is based on a 2004 student-run survey. 
varies across graduate degrees, this may drive some of the observed variation in work rates.

To test for such possible selection, using the NSCG sample reflected in Table 1, we compare mean father's education between mothers and non-mothers. Both overall and within each degree, mothers come from a more educated background. The mean level difference between fathers' education is largest for women who get an MD (approximately 1 year of schooling, significant at the 10 percent level), and roughly half as big for JDs, PhDs, and MBAs. ${ }^{62}$ Thus in the NSCG sample we find some evidence of positive selection into parenthood, which is strongest for MDs and may explain part of their higher labor force participation.

To test for this in the Harvard sample, for those women with a graduate degree we compare the proportion who attended a top-10 graduate program. By this admittedly noisy measure, in this sample we find no evidence of selection into parenthood on ability. The mean proportion who attended a top-10 graduate program is almost exactly equal among mothers and non-mothers, both for the sample as a whole and within each graduate degree.

Because the Harvard longitudinal sample focuses on mothers who have their first birth more than 10 years after graduation, we also consider whether there is evidence of selection on ability into 'late' motherhood. For MBAs (and to a lesser extent MAs), we do find some evidence of positive selection. Whereas among 'early' MBA mothers only 56 percent attended a top-10 program, a significantly higher 79 percent of late mothers did so.

Comparing these late mothers to non-mothers, we generally find no difference in the proportion who attended a top-10 program by the family-friendliness of their 10th-year work environment. The one exception is again among MBAs. Among those who worked in a nonfamily-friendly environment, 89 percent of the women who ultimately had children attended a top-10 program, compared to 71 percent of non-mothers (significantly different at the 10 percent level). There is no such difference among the MBAs who worked in a family-friendly environment.

In combination, these two findings suggest that within the longitudinal sample of Harvard mothers, the MBAs are an especially high-ability group. This selection may therefore bias downwards the level difference in labor force participation between these MBAs and the mothers with other graduate degrees.

\footnotetext{
${ }^{62}$ The p-values for these differences lie just above standard significance cut-offs.
} 


\section{Other Tables}

Tables A-5 and A-6 list the coefficients on the prediction of graduate degree type, given characteristics observable at graduation from college. The first lists these results for the NSCG sample, the second for the Harvard sample.

Table A-7 then reports the marginal effects for the controls included in the labor supply probits reported in Table 6 . The first two columns reflect the probits using the NSCG sample, and the last two columns the Harvard sample. Within each set of columns, the first lists results corresponding to Line (2) of each panel of Table 6, and the second the results for Line (3). 
Table A-5: Predicting Graduate Degree: NSCG Sample

\begin{tabular}{|c|c|c|c|c|c|}
\hline & MD & PhD & JD & MBA & MA \\
\hline \multicolumn{6}{|c|}{ Undergraduate Major: (excluded = English) } \\
\hline Biology & $\begin{array}{r}0.236^{* *} \\
(0.065)\end{array}$ & $\begin{array}{l}0.096^{*} \\
(0.045)\end{array}$ & $\begin{array}{c}-0.072^{* *} \\
(0.010)\end{array}$ & $\begin{array}{c}-0.065^{* *} \\
(0.014)\end{array}$ & $\begin{array}{l}-0.128^{*} \\
(0.054)\end{array}$ \\
\hline $\begin{array}{l}\text { Engineering \& } \\
\text { computer science }\end{array}$ & & $\begin{array}{c}0.056 \\
(0.056)\end{array}$ & $\begin{array}{c}-0.043^{* *} \\
(0.009)\end{array}$ & $\begin{array}{l}0.096^{+} \\
(0.052)\end{array}$ & $\begin{array}{l}-0.059 \\
(0.070)\end{array}$ \\
\hline Other sciences & $\begin{array}{c}0.018 \\
(0.025)\end{array}$ & $\begin{array}{l}0.158^{*} \\
(0.062)\end{array}$ & $\begin{array}{c}-0.032^{* *} \\
(0.008)\end{array}$ & $\begin{array}{r}-0.042^{*} \\
(0.016)\end{array}$ & $\begin{array}{l}-0.016 \\
(0.063)\end{array}$ \\
\hline Psychology & $\begin{array}{c}0.033 \\
(0.031)\end{array}$ & $\begin{array}{c}0.144^{* *} \\
(0.055)\end{array}$ & $\begin{array}{c}-0.035^{* *} \\
(0.008)\end{array}$ & $\begin{array}{c}-0.048^{* *} \\
(0.015)\end{array}$ & $\begin{array}{c}0.010 \\
(0.056)\end{array}$ \\
\hline Economics & & $\begin{array}{r}-0.059^{+} \\
(0.031)\end{array}$ & $\begin{array}{l}-0.016 \\
(0.010)\end{array}$ & $\begin{array}{c}0.263^{* *} \\
(0.061)\end{array}$ & $\begin{array}{r}-0.219^{* *} \\
(0.059)\end{array}$ \\
\hline Political Science & & $\begin{array}{l}-0.019 \\
(0.046)\end{array}$ & $\begin{array}{l}0.081^{*} \\
(0.039)\end{array}$ & $\begin{array}{l}-0.024 \\
(0.025)\end{array}$ & $\begin{array}{r}-0.130^{+} \\
(0.075)\end{array}$ \\
\hline Other social studies & $\begin{array}{l}-0.024 \\
(0.016)\end{array}$ & $\begin{array}{l}-0.007 \\
(0.035)\end{array}$ & $\begin{array}{c}-0.037^{* *} \\
(0.010)\end{array}$ & $\begin{array}{l}-0.041^{*} \\
(0.017)\end{array}$ & $\begin{array}{c}0.183^{* *} \\
(0.046)\end{array}$ \\
\hline History & $\begin{array}{c}0.005 \\
(0.038)\end{array}$ & $\begin{array}{c}0.050 \\
(0.074)\end{array}$ & $\begin{array}{c}0.049 \\
(0.040)\end{array}$ & $\begin{array}{l}-0.011 \\
(0.040)\end{array}$ & $\begin{array}{r}-0.216^{*} \\
(0.101)\end{array}$ \\
\hline Small major & $\begin{array}{c}-0.026^{* *} \\
(0.007)\end{array}$ & $\begin{array}{r}-0.036^{+} \\
(0.020)\end{array}$ & $\begin{array}{c}0.002 \\
(0.014)\end{array}$ & $\begin{array}{c}0.019 \\
(0.021)\end{array}$ & $\begin{array}{c}0.097^{* *} \\
(0.036)\end{array}$ \\
\hline Liberal arts college & $\begin{array}{r}-0.015^{+} \\
(0.009)\end{array}$ & $\begin{array}{l}-0.029 \\
(0.024)\end{array}$ & $\begin{array}{c}0.003 \\
(0.014)\end{array}$ & $\begin{array}{l}-0.020 \\
(0.018)\end{array}$ & $\begin{array}{l}0.079^{+} \\
(0.042)\end{array}$ \\
\hline $\begin{array}{l}\text { Private undergraduate } \\
\text { institution }\end{array}$ & $\begin{array}{l}0.023^{*} \\
(0.011)\end{array}$ & $\begin{array}{c}0.033 \\
(0.021)\end{array}$ & $\begin{array}{c}0.003 \\
(0.010)\end{array}$ & $\begin{array}{c}0.019 \\
(0.015)\end{array}$ & $\begin{array}{c}-0.105^{* *} \\
(0.033)\end{array}$ \\
\hline Minority & $\begin{array}{l}0.024^{+} \\
(0.014)\end{array}$ & $\begin{array}{c}0.031 \\
(0.025)\end{array}$ & $\begin{array}{c}0.023 \\
(0.015)\end{array}$ & $\begin{array}{c}-0.012 \\
(0.016)\end{array}$ & $\begin{array}{c}-0.113^{* *} \\
(0.038)\end{array}$ \\
\hline \multicolumn{6}{|c|}{ Region in High School: (excluded = West) } \\
\hline Northeast & $\begin{array}{l}-0.006 \\
(0.014)\end{array}$ & $\begin{array}{l}-0.046 \\
(0.029)\end{array}$ & $\begin{array}{c}0.006 \\
(0.020)\end{array}$ & $\begin{array}{c}0.026 \\
(0.035)\end{array}$ & $\begin{array}{c}0.042 \\
(0.059)\end{array}$ \\
\hline Mid-Atlantic & $\begin{array}{c}-0.021^{*} \\
(0.010)\end{array}$ & $\begin{array}{l}-0.016 \\
(0.029)\end{array}$ & $\begin{array}{l}-0.003 \\
(0.015)\end{array}$ & $\begin{array}{l}-0.028 \\
(0.020)\end{array}$ & $\begin{array}{l}0.089^{+} \\
(0.048)\end{array}$ \\
\hline Midwest & $\begin{array}{c}0.001 \\
(0.014)\end{array}$ & $\begin{array}{l}-0.027 \\
(0.028)\end{array}$ & $\begin{array}{c}0.003 \\
(0.016)\end{array}$ & $\begin{array}{c}0.023 \\
(0.027)\end{array}$ & $\begin{array}{c}-0.003 \\
(0.050)\end{array}$ \\
\hline South & $\begin{array}{l}-0.013 \\
(0.011)\end{array}$ & $\begin{array}{l}-0.026 \\
(0.028)\end{array}$ & $\begin{array}{l}-0.005 \\
(0.014)\end{array}$ & $\begin{array}{c}0.001 \\
(0.024)\end{array}$ & $\begin{array}{c}0.075 \\
(0.047)\end{array}$ \\
\hline Sample Size & 1404 & 1404 & 1404 & 1404 & 1404 \\
\hline Pseudo $\mathrm{R}^{2}$ & 0.31 & 0.08 & 0.24 & 0.24 & 0.10 \\
\hline Adjusted $\mathrm{R}^{2}$ & 0.18 & 0.04 & 0.13 & 0.18 & 0.11 \\
\hline
\end{tabular}

NOTES:

Each column reflects the coefficients from a different probit regression in which the dependent variable is whether each woman $i$ holds a degree of type $j$, where $j$ is equal to the degree type listed at the top of the column. We also include as right-hand side variables: additional measures of undergraduate school type (e.g., research university), mother's and father's education, citizenship status, whether the respondent lived outside the U.S. in high school, and age at arrival in the U.S.. (For predicting MDs, we grouped engineering and computer science with other sciences, and economics and political science with other social studies.) We report the marginal effects (with standard errors in parentheses). Significance is defined as **, *, and ${ }^{+}$ significant at the $1 \%, 5 \%$, and $10 \%$ level, respectively. The foot of the table reports the pseudo $\mathrm{R}^{2}$ for the probit itself, and the adjusted $\mathrm{R}^{2}$ if we instead use OLS. 
Table A-6: Predicting Graduate Degree: Harvard Sample

\begin{tabular}{|c|c|c|c|c|c|c|}
\hline & MD & PhD & JD & MBA & MA & None \\
\hline \multicolumn{7}{|c|}{ Undergraduate Major: (excluded = English) } \\
\hline Biology & $\begin{array}{c}0.613^{* *} \\
(0.066)\end{array}$ & $\begin{array}{c}0.032 \\
(0.041)\end{array}$ & $\begin{array}{c}-0.203^{* *} \\
(0.019)\end{array}$ & $\begin{array}{l}-0.061 \\
(0.037)\end{array}$ & $\begin{array}{c}-0.131^{* *} \\
(0.025)\end{array}$ & $\begin{array}{c}-0.143^{* *} \\
(0.022)\end{array}$ \\
\hline $\begin{array}{l}\text { Other sciences \& } \\
\text { engineering }\end{array}$ & $\begin{array}{c}0.047 \\
(0.075)\end{array}$ & $\begin{array}{c}0.310^{* *} \\
(0.095)\end{array}$ & $\begin{array}{c}-0.146^{* *} \\
(0.028)\end{array}$ & $\begin{array}{r}-0.088^{*} \\
(0.038)\end{array}$ & $\begin{array}{l}-0.051 \\
(0.050)\end{array}$ & $\begin{array}{l}-0.038 \\
(0.053)\end{array}$ \\
\hline Psychology & $\begin{array}{c}0.087 \\
(0.060)\end{array}$ & $\begin{array}{l}-0.006 \\
(0.032)\end{array}$ & $\begin{array}{c}-0.094^{* *} \\
(0.035)\end{array}$ & $\begin{array}{c}0.046 \\
(0.052)\end{array}$ & $\begin{array}{c}0.032 \\
(0.049)\end{array}$ & $\begin{array}{l}-0.030 \\
(0.041)\end{array}$ \\
\hline Economics & $\begin{array}{r}-0.069^{+} \\
(0.041)\end{array}$ & $\begin{array}{l}-0.057^{*} \\
(0.023)\end{array}$ & $\begin{array}{c}-0.100^{* *} \\
(0.035)\end{array}$ & $\begin{array}{c}0.371^{* *} \\
(0.077)\end{array}$ & $\begin{array}{c}-0.104^{* *} \\
(0.030)\end{array}$ & $\begin{array}{c}0.003 \\
(0.048)\end{array}$ \\
\hline Political science & $\begin{array}{l}-0.064 \\
(0.047)\end{array}$ & $\begin{array}{l}-0.055^{*} \\
(0.024)\end{array}$ & $\begin{array}{c}0.241^{* *} \\
(0.078)\end{array}$ & $\begin{array}{c}0.080 \\
(0.065)\end{array}$ & $\begin{array}{c}-0.105^{* *} \\
(0.031)\end{array}$ & $\begin{array}{r}-0.088^{*} \\
(0.035)\end{array}$ \\
\hline Anthropology & $\begin{array}{c}0.218^{* *} \\
(0.080)\end{array}$ & $\begin{array}{l}-0.042 \\
(0.026)\end{array}$ & $\begin{array}{c}-0.158^{* *} \\
(0.025)\end{array}$ & $\begin{array}{c}-0.086^{*} \\
(0.034)\end{array}$ & $\begin{array}{c}0.192^{*} \\
(0.075)\end{array}$ & $\begin{array}{l}-0.041 \\
(0.044)\end{array}$ \\
\hline Other social studies & $\begin{array}{l}-0.094^{*} \\
(0.038)\end{array}$ & $\begin{array}{l}-0.036 \\
(0.031)\end{array}$ & $\begin{array}{l}-0.002 \\
(0.057)\end{array}$ & $\begin{array}{l}0.188^{*} \\
(0.080)\end{array}$ & $\begin{array}{l}-0.029 \\
(0.048)\end{array}$ & $\begin{array}{l}-0.021 \\
(0.051)\end{array}$ \\
\hline History & $\begin{array}{c}0.091 \\
(0.060)\end{array}$ & $\begin{array}{l}-0.019 \\
(0.030)\end{array}$ & $\begin{array}{c}0.029 \\
(0.050)\end{array}$ & $\begin{array}{c}0.041 \\
(0.050)\end{array}$ & $\begin{array}{c}-0.085^{* *} \\
(0.032)\end{array}$ & $\begin{array}{l}-0.022 \\
(0.041)\end{array}$ \\
\hline Small major & $\begin{array}{c}0.010 \\
(0.048)\end{array}$ & $\begin{array}{c}-0.052^{*} \\
(0.021)\end{array}$ & $\begin{array}{c}0.070 \\
(0.056)\end{array}$ & $\begin{array}{r}-0.073^{*} \\
(0.030)\end{array}$ & $\begin{array}{l}0.108^{+} \\
(0.056)\end{array}$ & $\begin{array}{l}-0.007 \\
(0.045)\end{array}$ \\
\hline $\begin{array}{l}\text { Played sports } \\
\text { in college }\end{array}$ & $\begin{array}{l}-0.002 \\
(0.030)\end{array}$ & $\begin{array}{l}-0.047^{*} \\
(0.020)\end{array}$ & $\begin{array}{l}-0.041 \\
(0.031)\end{array}$ & $\begin{array}{c}0.036 \\
(0.028)\end{array}$ & $\begin{array}{l}0.064^{*} \\
(0.032)\end{array}$ & $\begin{array}{l}-0.014 \\
(0.028)\end{array}$ \\
\hline Private high school & $\begin{array}{c}0.018 \\
(0.029)\end{array}$ & $\begin{array}{l}-0.005 \\
(0.020)\end{array}$ & $\begin{array}{l}-0.002 \\
(0.030)\end{array}$ & $\begin{array}{c}0.031 \\
(0.026)\end{array}$ & $\begin{array}{l}-0.008 \\
(0.027)\end{array}$ & $\begin{array}{l}-0.027 \\
(0.027)\end{array}$ \\
\hline Minority & $\begin{array}{c}0.077^{+} \\
(0.044)\end{array}$ & $\begin{array}{c}-0.068^{* *} \\
(0.017)\end{array}$ & $\begin{array}{c}0.035 \\
(0.042)\end{array}$ & $\begin{array}{c}0.051 \\
(0.038)\end{array}$ & $\begin{array}{l}-0.020 \\
(0.036)\end{array}$ & $\begin{array}{l}-0.045 \\
(0.033)\end{array}$ \\
\hline \multicolumn{7}{|c|}{ Region in High School: (excluded = California) } \\
\hline Northeast & $\begin{array}{l}-0.011 \\
(0.044)\end{array}$ & $\begin{array}{l}-0.039 \\
(0.029)\end{array}$ & $\begin{array}{c}0.032 \\
(0.058)\end{array}$ & $\begin{array}{c}0.029 \\
(0.047)\end{array}$ & $\begin{array}{c}0.041 \\
(0.048)\end{array}$ & $\begin{array}{l}-0.047 \\
(0.039)\end{array}$ \\
\hline Mid-Atlantic & $\begin{array}{c}0.004 \\
(0.044)\end{array}$ & $\begin{array}{c}0.004 \\
(0.034)\end{array}$ & $\begin{array}{c}0.055 \\
(0.058)\end{array}$ & $\begin{array}{c}0.020 \\
(0.045)\end{array}$ & $\begin{array}{c}-0.032 \\
(0.041)\end{array}$ & $\begin{array}{l}-0.040 \\
(0.038)\end{array}$ \\
\hline District of Columbia & $\begin{array}{r}-0.076^{+} \\
(0.042)\end{array}$ & $\begin{array}{c}0.014 \\
(0.049)\end{array}$ & $\begin{array}{l}0.203^{*} \\
(0.096)\end{array}$ & $\begin{array}{c}0.016 \\
(0.065)\end{array}$ & $\begin{array}{c}0.021 \\
(0.063)\end{array}$ & $\begin{array}{r}-0.119^{* *} \\
(0.028)\end{array}$ \\
\hline South & $\begin{array}{l}-0.055 \\
(0.045)\end{array}$ & $\begin{array}{c}0.021 \\
(0.049)\end{array}$ & $\begin{array}{l}0.202^{*} \\
(0.092)\end{array}$ & $\begin{array}{c}0.080 \\
(0.072)\end{array}$ & $\begin{array}{c}-0.115^{* *} \\
(0.032)\end{array}$ & $\begin{array}{r}-0.077^{+} \\
(0.040)\end{array}$ \\
\hline Midwest & $\begin{array}{l}-0.023 \\
(0.049)\end{array}$ & $\begin{array}{c}0.003 \\
(0.041) \\
\end{array}$ & $\begin{array}{c}0.125 \\
(0.080) \\
\end{array}$ & $\begin{array}{c}0.049 \\
(0.062) \\
\end{array}$ & $\begin{array}{c}-0.090^{*} \\
(0.038)\end{array}$ & $\begin{array}{l}-0.048 \\
(0.044)\end{array}$ \\
\hline Sample Size & 829 & 829 & 829 & 829 & 829 & 829 \\
\hline Pseudo $\mathrm{R}^{2}$ & 0.24 & 0.17 & 0.14 & 0.15 & 0.12 & 0.07 \\
\hline Adjusted $\mathrm{R}^{2}$ & 0.22 & 0.08 & 0.09 & 0.10 & 0.06 & 0.01 \\
\hline
\end{tabular}

NOTES:

Sample excludes those women that we cannot observe in the graduation yearbooks. We also include as right-hand side variables majoring in arts or cultural studies, undergraduate year and dorm, attendance at a private high school, whether an individual grew up in a top- 25 city or in a low-density state, or in the west (other than CA) or outside the U.S. See the foot of Table A-5 for additional notes. 
Table A-7: Full Labor Supply Probit Marginal Effects

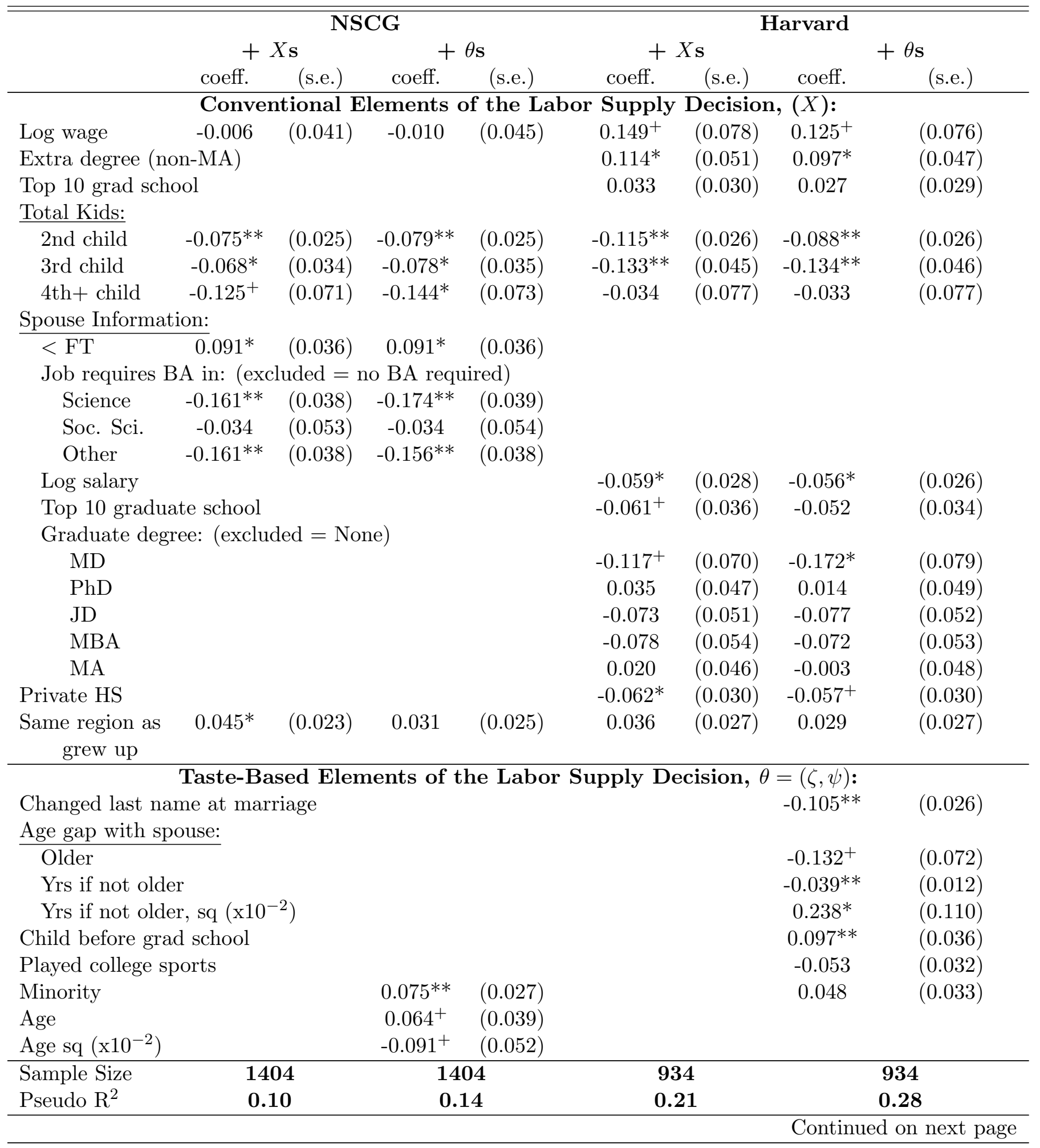


Table A-7 - continued from previous page

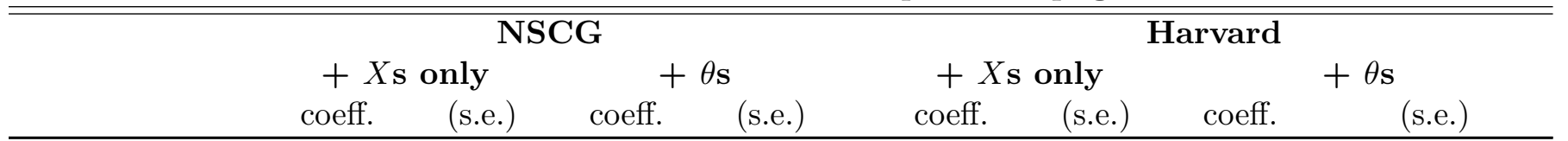

NOTES:

Each double set of columns reflects the results from a different probit regression of labor force participation. The first two sets report the results in the NSCG sample, the second two sets for the Harvard sample. Within each set, the first columns report the coefficients when only conventional elements of the married women's labor supply model $(X)$ are included, corresponding to the results reported on Line (2) of each panel of Table 6.The second set reports the results when we also include proxies for unobserved taste $(\theta$, corresponding to Line (3)). In the NSCG regressions we also include as right-hand side variables the following factors: year of graduation (from graduate school), age at high school and college graduation, undergraduate major and whether it was a small major, undergraduate and graduate school type (e.g., private, research university, liberal arts college), detailed mothers' and fathers' education, citizenship, age at arrival in U.S. and reason for coming, and current region and region in high school. In the Harvard regressions, we also include: year of graduation (from undergraduate and graduate school), whether the individual has an MA in addition to their primary degree, undergraduate major and whether it was a small major, whether their husband attended a top-20 undergraduate institution, undergraduate dorm, region in high school and whether they grew up in a big city and/or in a low-density state, and current region. We report the marginal effects (with standard errors in parentheses). Significance is defined as ${ }^{* *},{ }^{*}$, and ${ }^{+}$significant at the $1 \%, 5 \%$, and $10 \%$ level, respectively. 